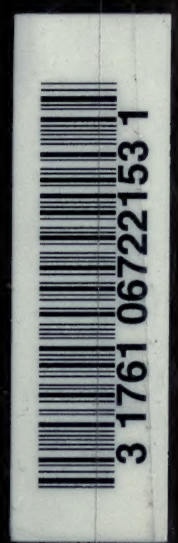

GERSTEIN

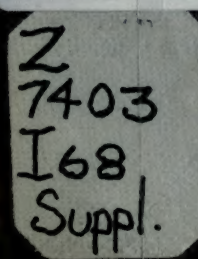

UNIV.OF

TORONTO LIBRARU. 




SUPPLEMENTARY

\section{LIST OF JOURNALS.}




\section{INTERNATIONAL COUNCIL.}

Prof. H. E. ARMSTRONG (United Kingdom).

Dr. W. T. BLANFORD (INDIA).

Prof. Dr. A. von BÖHM (AUSTRIA).

DR. J. BRUNCHORST (NORWAY).

DR. E. W. DAHLGREN (SWEDEN).

Prof. A. FAMINTZIN (RUssia).

Prof. Dr. J. H. GRAF (Switzertand).

Prof. J. W. GREGORY (VICtoria).

Dr. M. KNUDSEN (DENMARK).

Prof. D. J. KORTEWEG (Holland).

Prof. H. LAMB (S. Australia).

Prop. S. P. LANGLeY (United States).

Mons. D. MÉTAXAS (GREeOE).

Prof. R. NASINI (Italy).

DON F. DEL PASO Y TRONCOSO (MeXICO).

Prof. H. POINCARE (France).

Prof. GUSTAT RADOS (HUNGARY).

PROF. J. SAKURAI (JAPAN).

R. TRIMEN, Esq. (CAPE Colony).

Prof. Dr. O. UHLWORM (Germany).

\section{EXECUTIVE COMMITTEE.}

DR. CYRUS ADLER.

Prof. H. E. ARMSTRONG.

Prof. A. FAMINTZIN.

Dr. J. LARMOR, Sec. R.S.

DR. L. MOND.

Prof. R. NASINI.

Prof. H. POINCARE.

Prof. T. E. THORPE.

Prof. Dr. O. UHLWORM.

\section{DIRECTOR.}

DR. H. FORSTER MORLEY 


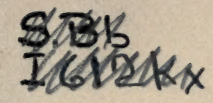

\section{INTERNATIONAL CATALOGUE III \\ or}

\section{SCIENTIFIC LITERATURE}

\section{SUPPLEMENTARY}

\section{LIST OF JOURNALS}

WITH ABBREVIATIONS USED IN THE CATALOGUE AS REFERENCES

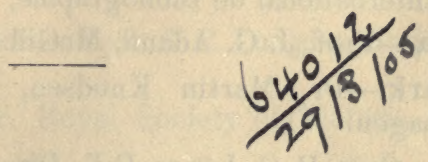

PUBLISHED FOR THE INTERNATIONAL COUNCIL

BI THE

ROYAL SOCIETY OF LONDON

LONDON :

Harrison and Sons, 45, St. Martin's Lane.

France: GaUthier-Vilitars, Paris.

Germany: Hermann Paetel, Berlin. 


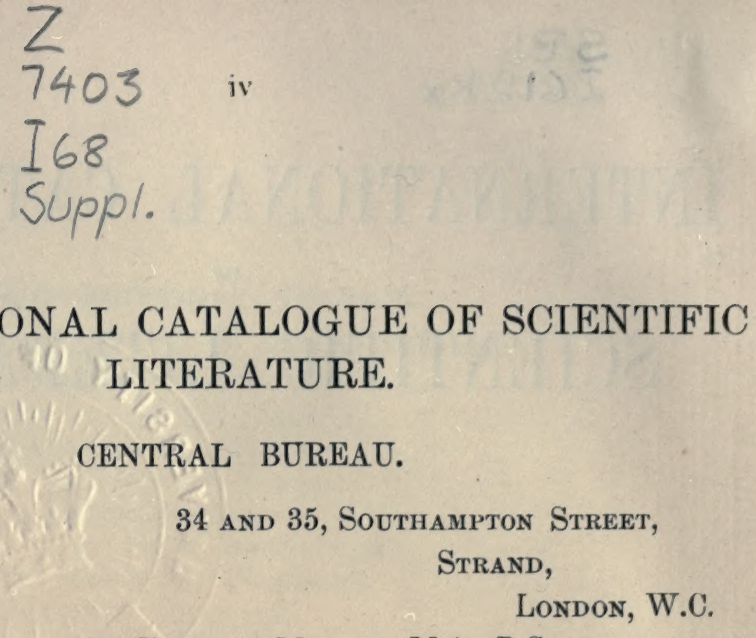

Director.-H. Forster Morley, M.A., D.Sc.

\section{REGIONAL BUREAUS.}

All communications for the several Regional Bureaus are to be sent to the addresses here given.

Austria.-Herr Dr. J. Karabaček, Direktor, K. K. Hofbibliothek, Vienna.

Belgium.-Monsieur Louis Masure, Secrétaire-Général de l'Office International de Bibliographie, Brussels.

Canada._Prof. J. G. Adami, McGill College, Montreal.

Denmark.-Dr. Martin Knudsen, Frederikshaldsgade 15, Copenhagen. Ö.

Egypt.-Capt. H. G. Lyons, R.E., Director-General, Survey Department Cairo.

Finland.-Herr Hjalmar Lenning, Bibliothekar der Societät der Wissenschaften, Helsingfors.

France.-Monsieur le Dr. J. Deniker, 8, Rue de Buffon, Paris.

Germany.-Herr Prof. Dr. 0. Uhlworm, Enckeplatz, 3A, Berlin, S.W. Greece.-Monsieur D. Métaxas, Minister Plenipotentiary for Greece, Greek Legation, 1, Stanhope Gardens, S.W.

Holland.-Heer Prof. D. J. Korteweg, Universität, Amsterdam.

Hungary.-Herr Gustav Rados, viii, Muzeumkörut, Mủegyetem, Buda-Pest.

India and Ceylon.-The Hon. Sec., Asiatic Society of Bengal, 57, Park Street, Calcutta.

Italy.-Cav. E. Mancini, Accademia dei Lincei, Palazzo Corsinı, Lungara, Rome. 
Japan.-Prof. J. Sakurai, Imperial University, Tokyo.

Mexico.-Señor Don José M. Vigil, Presidente del Instituto Bibliografico Mexicano, Biblioteca Nacional, Mexico City.

New South Wales.-The Hon. Sec., Royal Society of New South Wales, Sydney.

New Zealand.-Sir James Hector, K.C.M.G., Director of the New Zealand Institute, Wellington, N.Z.

Norway.-Dr. J. Brunchorst, Bergenske Museum, Bergen.

Poland (Austrian, Russian and Prussian).-Dr. T. Estreicher, Sekretär, Komisya Bibliograficzna, Akademii Umiejętności, Cracow.

Portugal.-Senhor F. Gomez Teixeira, A cademia Polytechnica do Porto, Oporto.

Queensland.-John Shirley, Esq., B.Sc., Cordelia Street, South Brisbane.

Russia.-Monsieur E. Heintz, l'Observatoire Physique Central Nicolas, Vass. Ostr. 23-me ligne, 2, St. Petersburg.

South Africa.-L. Péringuey, Esq., South African Museum, Cape Town, Cape of Good Hope.

South Australia.-The Librarian, Public Library of South Australia, Adelaide.

Sweden.-1)r. E. W. Dahlgren, Royal Academy of Sciences, Stockholm.

Switzerland.-Herr Prof. Dr. J. H. Graf, Schweizerische Landesbibliothek, Bern.

The United States of America.-Prof. S. P. Langley, Smithsonian Institution, Washington.

Victoria.-Prof. J. W. Gregory, Royal Society of Victoria, Victoria Street, Melbourne.

Western Australia.-J. S. Battye, Esq., Victoria Public Library, Perth. 


\section{DIRECTIONS.}

The present volume contains a supplementary list of the periodicals that are examined by the Regional Bureaus engaged in the preparation of the index slips used in the volumes of the International Catalogue of Scientific Literature.

It consists of the complete list of Austrian periodicals, and of additions to the lists for other countries which were published in the List of Journals issued in 1903.

The list prepared by each Regional Bureau is divided into three columns. The first column contains the abbreviation used in the Catalogue to represent the periodical. The second column contains the full title of the journal and its place of publication. The third column contains a number. These numbers are usually consecutive, and are referred to in the short lists given at the end of each volume of the Catalogue.

In respect of each periodical, the last entry in the second column is one or more of the letters A to R. These letters denote the sciences under which it is thought that scientific papers occurring in the periodical are likely to be catalogued. Where the indication is $[A-R]$ it is to be understood that papers belonging to all branches of science may be looked for in the periodical to the title of which these letters are attached. 


\section{CON'ENT'S.}

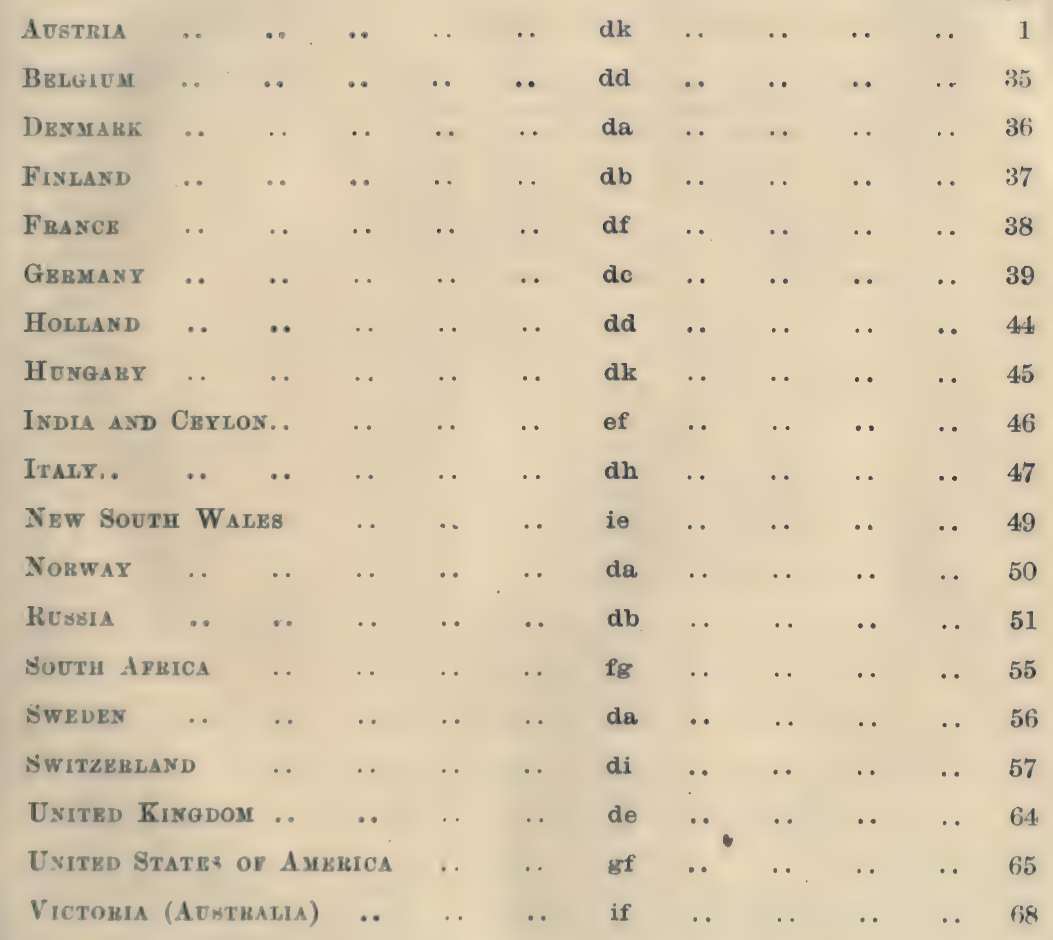


Allg. TextilZtg, Wien .. Allgemeine Textil-Zeitung. Wien. [alle 9 Tage.]

Allg. VersichZtg, Wien .. Allgemeine Versicherungszeitung. Wien. $\left[\frac{1}{2}\right.$

Allg. WeinZtg, Wien .. Allgemeine Weinzeitung. Illustrierte Zeitung für Weinbau und Kellerwirtschaft. Herausgeg. v. Hugo H. Hitschmann. Red. v. Antonio dal Piaz. Wien. [wöchentl.] [M

Allg. Wr. Med. Ztg _. Allgemeine Wiener Medizinische Zeitung. Red. v. Ed. Kraus. Wien. [wöchentl.] [OQR

Allg. Zs. Bierbr. Malz- Allgemeine Zeitschrift für Bierbrauerei und fabr., Wien Malzfabrikation. Herausgeg. v. Karl Fasbender. Wien. [wöchentl.] [BD

Alpenl. HolzZtg, Graz .. Alpenländische Holz-Zeitung. Fachblatt für Holzhandel, Holzverwertung, Forstwirtschaft, Loherzeugung und Zellulosefabrikation. Graz.

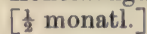

[BD

Alpi Giulie, Triest .. Alpi Giulie. Trieste. [8 N. all'anno] [P 23

Arch. Dermat. Syph., Wien

Archiv für Dermatologie und Syphilis. Red. v. F.J. Pick. Wien und Leipzig. [monatl.]

OQR

Arch. Math. Phys., Prag

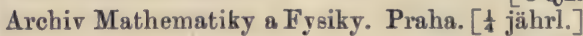

$[\mathrm{ABC}$

Arch. Natw. LdDurchf. Archiv der Naturwissenschaftlichen Landes. Böhmen, Prag durchforschung von Böhmen. Prag. [zwanglos.]

Arch. Př́rod. Výzk. Čech., Archiv pro Přrodovědecký Výzkum Čech. Praha. Prag [Archiv der Naturhistorischen Landesdurchforschung von Böhmen. Tschechische Ausgabe von 26.$]$

Archeogr. Triestino, Triest

L'Archeografo Triestino. Raccolta di Opuscoli e Notizie per Trieste e per l'Istria. Trieste. [trimestr.]

Archivio Trentino, Trento . Archivio Trentino. Pubblicato per Cura della Direzione della Biblioteca e del Museo Comu. nali di Trento. Trento. [trimestr.]

Archit. Baumstr.Ztg, Wien Architekten- und Baumeister-Zeitung. Red.v. Peter Bambach. Wien. [2 wöchentl.] [B Architekt, Wien .. . . Der Architekt. Wiener Monatshefte für Bauwesen und Dekorative Kunst. Redigiert von F[erdinand Ritter Fellner] $\mathbf{v}$ [on] Felldegg. Wien. [monatl.]

Argo, Laibach . . . . Argo. Zeitschrift für Krainische Landeskunde. Herauseg. v. Alfons Müllner. Laibach. [monatl.]

[P

Aus Deutschen Bergen, Aus Deutschen Bergen. Blätter für Freunde Warnsdorf der Deutschen Bergwelt . . . . Verbandsblatt der Gebirgsvereine für das Böhmische Mittelgebirge .... Herausgeg. v. F. W. Krondorf und Max Heyssler. Warnsdorf. [monatl.] [P

\section{B}

Baukeramik, Wien _. Baukeramik. Neue Folge des Zentralanzeigers. Zeitschrift für Bauwesen, Ziegel-, Ton-, Mörtel- und verw[andte] Industrien, Betonbau und Muterialprüfung der Technik. Wien,

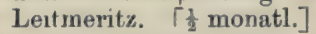

Bautechn., Wien .. . . Der Bautechniker. Zentralorgan für das Österreichische Bauwesen. Zeitschrift für Buuund Verkehrswesen, Technik und Gewerbe. Wien. [wöchentl.] 
Beitr. DtschBöhm. Tolksk., Prag

Beitr. Ldkde. Öst. o. Enns, Linz

Beitr. Psych. Klinik, Wien

Biene, Böhmisch-Leipa ..

Bienenzüchter, Klosterneu. burg

Bl. Klin. Hydrother., Wien

Bökm. Bierbrauer, Prag ..

Boll. Agrar. Dalm., Zara

Boll. Med. Trent.,Trento. .

Bot. LitBl., Innsbruck ..

Bote Tir. Vorarlberg, Innsbruck

Brautechn. Rdsch., Mährisch-Ostrau

Bregenz, JahrBer. Mиs. Ver.

Bregenz, Mitt. Vorarlbg. LaudvVer.

Brizen, Mitt. Brix. Wasser. heilanst.

Brïn, Ber. Met. Komm..

Brïnn, Ber. MusSekt. Tätigkeitsbericht der Museumssektion der k. k MährGes. Bef. Landw.

Briinn, Čas. Mor. Mus. Zemsk.

Briann, JahrBer. Mähr. Ges. Bef. Landw.
Beitrüge zur Deutsch-Böhmischen Volkskunde. Im Auftrage der Gesellschaft zur Förderung Deutscher Wissenschaft, Kunst und Literatur in Böhmen geleitet von Adolf Hauffen. Prag. [zwanglos.]

Beiträge zur Landeskunde von Österreich ob der Enns. Linz. [jährl.; Beilage zu 173.] [P Beiträge zur Psychiatrischen Klinik. Heraus. geg. v. Robert Sommer. Wien und Berlin. [zwanglos.]

Die Biene. Böhmisch-Leipa. [2 wöchentl.]

Monatsblatt tür Bienenzüchter. Red. v. Theodor Weippl. Klosterneuburg. [monatl.]

$[\mathrm{N}$

Blatter für Klinische Hydrotherapie und verwandte Heilmethoden, herausgegeben von Wilhelm Winternitz. Wien und Leipzig. [monatl.] [DQR

Der Böhmische Bierbraner. Organ für die Interessen des gesamten Brauwesens. Herausgegeben von einem Brauerkonsortium. Prag. [1 monatl.]

Bollettino Agrario della Dalmazia. Zara. [bi-mensile.] [DMN

Il Bollettino Medico Trentino. Organo dell' Associazione Medica Tridentina. Red. dal G. B. Gerloni. Trento. [mensile.] [OQR Botanisches Literaturblatt. Organ für Autorund Instituts-Referate aus dem Gesamtgebiete der botanischen Literatur. Herausgeg. $u$. red. v. Adolf Wagner. Innsbruck.

monatl., nur referierend.] [M

Bote für Tirol und Vorarlberg. Innsbruck. [tägl.]

Brautechnische Rundschau. Mährisch-Ostrau. [1- $\frac{1}{2}$ monatl.]

Jahresbericht des Vorarlberger MuseumVereines. Bregenz. [jährl]

Mitteilungen des Vorarlbergischen Landwirtschaftsvereines. Red. v. Josef Koepruner. Bregenz. [monatl.]

[DMN

Mitteilungen aus der Brixener Wusserheilanstalt des Dr. Otto $\mathbf{v}[\mathrm{on}]$ Guggenberg. Brixen. [monatl.]

[DQR

Bericht der Meteorologischen Kommission des Naturforschenden V'ereines in Brünn. [jährl.] Mährischen Gesellschaft zur Beförderung der Landwirtschaft, der Natur- und Landeskunde. Brünn. [jährl.] [DMN Casopis Moravského Muzea Zemského. Red. Frant. Rypáęek, Frant. Šujan. Vydává Moravská Musejní Společnost. Brno [Zeit. schrift des Mälırischen Landesmuseums. Herausgegeben von der Mährischen Museums.

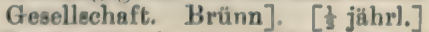
Jahresbericht der k. k. Mährischen Giesellschaft zur Beförderung der Landwirtschaft, der Natur- und Landeskunde. Brünn. [jähri.] 
Brinn, Mitt. Mähr. FischVer,

Brünn, Mitt. Mähr. GewMus.

Briinn, MonBer. ObstWeinGartBauSekt. MährGes. Bef. Landw.

Brïnn, MonSchr. TextilInd.

Brïnn, Vrela Moravské ..

Brünn, Verh. Forstw. Mähr. Schles.

Brïnn, Verh. Natf. Ver...

Brïnn, Zpráva Mus. Odb. Mor. Spol. Zvel. Hospod. Prirod. Vlast.

Brïnn, Zs. Mähr. Ld-Mus.

Bukow. Landw. Bl., Czernowitz

Bull. Arch. Stor. Dalm., Spalato

Carinthia I, Klagenfurt ..

Carinthia II, Klagenfurt .

Čas. Česk. Lékárn., Prag.

Čas. Česk. Ovocn., Troja..

Čas. Česk. Zvěrolék., Wall.Meseritsch
Mitteilungen des Mährischen Landes-FischereiVereines. Brünn. [2 monatl.]

Mitteilungen des Mährischen Gewerbe-Museums. Red. v. Julius Leisching. Brünn. Beilage zur Mährischen Gewerbe-Zeitung. [monatl.]

Monatsberichte der Obst-, Wein- und Gartenbausektion der k. k. Mährisch-Schlesischen Gesellschaft zur Beförderung des Arkerbaues, der Kultur und Landeskunde. Brünn. [M

Brünner Monatsschrift für Textilindustrie. Illustriertes Fachblatt. Organ des Vereines der Wollindustriellen Mährens in Brünn und des Brünner Textilklubs. Brünn. [monatl.]

V̌ela Moravské. Časopis Včelařů Moravskych. Brn. [Die Mährische Biene. Zeitschrift der Mährischen Bienenzüchter. Brünn.]

Verhandlungen der Forstwirte von Mähren und Schlesien. Zeitschrift des Mähr[isch]-Schles [ischen] Forstvereines und Organ der Forstlichen Landesversuchsstelle für Mähren und Schlesien. Red. v. Franz Kruetzl. Brünn.

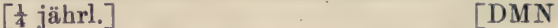

Verhandlungen des Naturforschenden Vereines in Brünn. Brünn. [jährl.]

Zpráva o Činnosti Musejnúho Odboru C. K. Moravské Spoleěnosti pro Zvelebené Hospo. dáŕství, Přrirodoznalství a Vlastivědy. Brno. [Nebentitel von 52.]

[DMN

Zeitschrift des Mährischen Landesmuseums. Herausgegeben von der Mährischen MuseumsGesellschaft. Red. v. A. Rzehak, C. Schir-

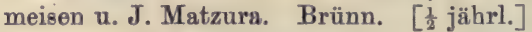

Bukowinaer Landwirtschaftliche Blätter. Offizielles Organ des Landeskulturvereines für das Herzogtum Bukowina. Red. v. Emil

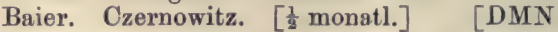
Bullettino di Archeologia e Storia Dalmata. Red. Fr. Bulič. Spalato. [wensile.]

Carinthia I.,Mitteilungen des Geschichtsvereines für Kärnten. Red. v. August von Jaksch. Klagenfurt. [2 monatl.]

Carinthia II ,Mitteilungen des Naturhistorischen Landesmuseums für Kärnten. Red. v. Karl Frauscher. Klagenfurt. [2 monatl.]

Časopis Českého Lékárnictva. Praha. [Zeitschrift für das Tschechische Apothekerwesen. Prag, monatl.]

$[\mathrm{DQ}$

Úasopis Českého Orocnictva. Troja. [Zeitschrift für den Tschechischen Obstbau, $\frac{1}{4}$ jährl.]

Časopis Českých Zvěrolékařů. [Zeitschrift der Tschechischen Tierärzte. Wall.-Meseritsch, t monatl.]

55

56

58 0 2 1

4

5
67 
C̆as. Jedn. Prof.ŠkolZeměd.|Časopis Jednot Professorů a Ǔcitelů Škol ZemèČesk. Moravsk., Rokycan dēlských v Král[ovství] Českém a Markr [abství] Moravském. Rokyean. [Zeitschrift des Vereines der Professoren und Lehrer an den Ackerbauschulen des Königreiches Böhmen und der Markgrafschaft Mähren. Rokycan,

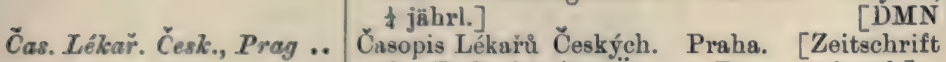

[DMN der Tschechischen Ärzte. Prag, wöchentl.]

Cas. Prìm. Chem., Prag .. Č́asopis pro Průnysl Chemický. Organ Společnosti pro Prưmysl Chemický v Království Českém. Red. Antonín Nydrle, František Štolba, Josef Burian. Praha. [Zeitschrift für Chemische Industrie. Organ der Gesellschaft für Chemische Industrie im Königreiche Böhmen. $10 \mathrm{~F}$. jährl.] [BD Časlan, Věstu. Mus. Arch. Vèstnik Museí a Archeologů Českoslovanských. Českoslov.

Črop. Kvas, Prag Red. Vácsl. Vl. Jeníček. Čáslav. [Anzeiger des 'Tschechoslavischen Archäologischen Museums. Caslau, monatl.]

Čsopis K̇as. Odborný List věnovaný Věskerým Zájmům Pivovarnictvi. Praba. [Meth-Zeitschrift. Fachblatt für alle Interessen der Bierbrauerei. Prag. $\frac{1}{2}$ monatl.] [BD Česka Flora, Prag . C Ceská Flora. Mèsičník pro Zalradníky Milovníky a Prátele Rostlin. Red. Martin Fulín. PrahaVršovice. [Tschechische Flora.Monatsblatt für

České Listy Hospod., Prag České Iisty Hospodářrské. Vèstník Üstřední Společnnsti Hospodářské pro Království České. Red. Frant. Sitenský. Praha. [Landwirtschaftliche Tscheohische Blätter. Anzeiger des landwirtschaftlichen Zentralvereines für das

Českoslov. Letop. Mus., Českoslovanské Letopisi Museini. Č́slav. [TscheČaslar

Českoslov. Mat. Rolnická, Českoslovanská Matice Rolnická. Chrudim. Chrudim [Tschechoslavische Iandwirtschafts-Mutter. 2 monatl.] [DMN

Ceský Lid, Prag .. . . C Ceský Lid. Sborník věnovaný Studiu Lidu Českéhov Čechách, na Moravĕ, ve Slezsku a na Slovensku. Red. M. Õ. Zíbrt. Praha. [Das Tschechische Volk. Magazin für das Studium des tschechischen Volkes in Böhmen, Mähren,

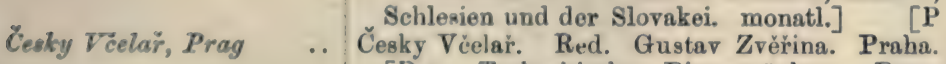
[Der Tschechische Bienenzüchter. Prag, monatl.] [N

Chmelařské Listy, Rakonitz Chmelařrské Listy. Organ Českého Chmelařského Spolku pro Královstivi České. Rakonitz. [Hopfenbaublätter. Organ des Trchechischen Hopfenbauvereines für das Königreich Bsimen. $16 \mathrm{H}$. jăhri.] [M

Czernovitz, Jahrb. Bukow. Jahrbuch des Bukowiner Landes-Museums. 
Danzers ArmeeZtg, Wien

Dtsch. Arbeit, Prag

Dtsch. Bienenzucht, Prag..

Dtsch. Landwirt, Prag ..

Dtsch. Rdsch. Geogr. Stat. Wien

EdelmetInd., Wien

Elektrotechn. NeuigkAnz., Wien

Elektrotechn., Wien

Enns, JahrBer. MusVer...

Epocha, Prag . . . .

Erdbebenwarte, Laibach ..

ErlafthlBote, Scheibbs ..
Danzers Armee-Zeitung. Redakteur des wissenschaftlichen Theiles A. Pichler. Wien. [wöchentl.]

[BCD

Jeutsche Arbeit. Zeitschrift für das geistige Leben der Deutschen in Böhmen. Herausgegeben im Auftrage der Gresellschaft zur Förderung Deutscher Wissenschaft, Kunst und Literatur in Böhmen. Prag und München. [monatl.]

Die Deutsche Bienenzucht in Theorie und Praxis. Prag. [Beilage zu 136.] [N Der Deutsche Landwirt. Organ des Deutschen Landwirtschaftlichen Zentralverbandes für Böhmen. Red. v. Felix Bassler. Prag. [2 wöchentl.]

DMN

Deutsche Rundschau für Geographie und Statistik. Herausgeg. v. Friedrich Umlauft. Wien. [monatl.]

\section{E}

gan der Juwelen-, Gold-, Silberbranche, Uhrenindustrie, Feinmechanik sowie verwandter Gewerbe. Herausgeg. v. Gustav Hor-

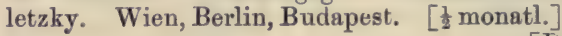

Elektrotechnischer Neuigkeits-Anzeiger und maschinentechnische Rundschau. Red. $v$. $\mathrm{Br}$ [uno] Böhm-Raffay. Wien. [monatl.]

[BC

Der Elektro-Techniker. Organ für angewandte Elektrizität mit besonderer Rücksichtnahme auf Telegraphie, Telephonie, elektrische Beleuchtung, Kraftübertragung und verwandte Zweige. Herausg. v. G. Ad[olf]

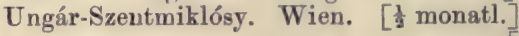

Jahresbericht des Museal-Vereines für Enns und Umgebung. Linz. [zwanglos.]

Obor Tre

Národohospodář̀ství, Prírodovèdy a Vynálezù se Zvláśtním Zřetelem ne Objevy Doby Nejnovšjěi, Revue Aeronautická. Red. Gustav Finger. Praha. [Epoche. Monatsblatt. Revue für zeitgemässe Betrachtung auf' dem Gebiete der Technik, Industrie, Handwerke, Kommunikation, [Nationalökonomie, Naturwissenschaft und Erfindungen, mit besonderer Berücksichtigung der Entdeckungen der neuesten Zeit, Äëronautische Revue. Prag. $\frac{1}{2}$ monatl.]

Die Erdbebenwarte. Monatsschrift herausgegeben von A. Belar. Laibach. [6 Doppelh. jährl.]

Erlafthal-Bote. Wochenschrift für Gewerbe, Industrie und Landwirtschaft. Scheibbs. [wöchentl.] 
ErzgebZtg, Teplitz .. Erzgebirgszeitung. Volkstümliche Monatsschrift für Nordwestböhmen. Herausgegeben vom Nordwestböhmischen GebirgsvereinsVerband. Geleitet von Julius Reinwarth. Teplitz. [monatl.]

\section{F}

Fachztg Gerber, Wien .. Fuchzeitung. Organ für die Interessen der Gerber und Lederarheiter Österreich-Ungarns. Wien. [ 1 monatl.]

[BD

Farmac. Rev., Josefstart

Farmaceutická Revue. Josefstadt. ['harmazeutische Revue, monatl.]

[DQ

Finanz. dssek Rev., Wien

monatl.]

Forst JagdZtg, Suaz .. Forst- und Jagdzeitung. Fachschrift des Vereines Deutacher Forstleute in Böhmen. Red. v. Karl Mayer. Saaz. [monatl.] [M

Fotogr. Věstn., Prag .. Fotografický Véstník. Praha. [Photographischer Anzeiger. Prag, monatl.]

Freie Künste, Wien _. Freie Künste. Fuchblatt für Lithographie, Steindruckerei, Buchdruckerei. Mit der Beilage "Graphische Musterblätter." Red. v. Josef Heim. Wien und Leipzig. Wien. [ monatl.]

Fricks Rdsch., Wien .. Fricks Rundschau. Belehrende und unterhalterde Mitteilungen für die Freunde der Land- und Forstwirtschaft, deз Garten-, Obst- und Weinbaues, der Haus- und Kellerwirtschaft, der Bienenzucht, des Sportes, der Jagd und Fischerei, der einschlägigen Wissenschaften und Gewerbe. Red. v. Karl Zentzycki. Wien. [ $\frac{1}{2}$ monatl. $]$ [DMN

\section{G}

Gärtn. Rdsch., Wien _. Gärtnerische Rundschau. Wien. [monatl.] [M Gambrinus, Wien.. .. Brauer- und Hopfen-Zeitung Gambrinus. Herausg. v. Siegmund Spitz und Adolf Lichtblau. Wien. [zumindest $\frac{1}{2}$ monatl.] [BD

GartenBörse, Wien _. Wiener Gartenbörse. Intelligenzblatt für Gürtnerei, Land- und Forstwirtschaft. Wien [M

Gastechniker, Wien .. Der Gastechniker. Fachblatt für die Gasindustrie, Wasserversorgung, Heizung und Ventilation. Eigentum, Verlag und Organ des Vereines der Gas. und Wasserfachmänner

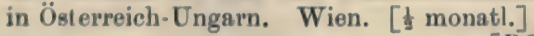

$[\mathrm{BCD}$

Geogr. JahrBer. Öst., Wien Geographischer Jahresbericht über Österreich. Red. v. Robert Sieger. Wien. [jäbrl., referierend]

Gerber-Courier, Wien .. Gerber-Courier. Erstes österreichisch-ungurisches Fachblatt für IJederfabrikation und Lederhandel. Herausg. v. Leopold Selıotz Witwe. Wien. [wöchentl.] [BD

Gerber, Wien .. .. Der Gerber. Organ der Chemisch-Technischen Versuchsanstalt für Lederindustrie. Organ des Vereines der Ledlerindustriellen Böhmene. Red. v. W. u. J. Eit:zer. Wien. [ $\frac{1}{8}$ monatl.] 
Gesundheit, Wien.. .. Die Gesundheit. Zeitschrift für Gesundheitspflege und Heilreform, für naturgemässe Lebensweise, Gesundheitssport, Erziehungsund Schulreform und Tierschutz. Herausgeg. v. A. del Torre. Ked. v. H. Müller. Wien. [monatl.]

[DQR

Giorn. Farmac., Trieste .. Giornale di Farmacia. Rivista Mensile di Chimica, Farmacia, Bromatologia ed Igiene. Organo Ufficiale die Gremii Farmacisti di Trieste, Ischia, Gorizia e della Società Farmaceutica Trentira. Trieste. [mensile.]

Gnosis, Wien .. . . Die Gnosis. Halbmonatschrift. Mit den Wissenschaftlichen Mitteilungen für Okkultismus. Wien. [t monatl.]

Görz, Gospod. List _. Gospodarski List. Glasilo C. Kr. Kmetijskega Drustva v Gorici. Urejuje: Viljens Dominko. Gorica: [Landwirtschaftliches Blatt. Organ der K. K. Ackerbau-Gesellschaft in Görz]. [monatl.]

$[\mathrm{DMN}$

Gorizia, Atti Soc. Agrar.. Atti o Memorie della I. R. Società Agraria di Gorizia. Organo dell'I.R.Istituto Spermmentale Chimico-Agrario e degli Istituti SeientificoAgrari Provinciali. Gorizia. [mensile.] [DMN

Graz, Jahr Rer. ObstbVer. MittSteierm.

Graz. Landw. Mitt.Steierm.

Jahresbericht des Obstbauvereines für Mittelsteiermark. Graz. [jährl.]

Landwirtschaftliche Mitteilungen für Steiermark. Organ für Land wirtschaft und Landeskultur. Herausgegeben von der k. k. Landwirtschafts-Gesellschaft in Steiermark. Graz. [l monatl.]

[DMN

Graz, Mitt. GartenbGes. Mitteilungen der k. k. Gartenbau-Gesellschaft Steierm. in Steiermark. Red. v. Lorenz Kristof. Graz. [monatl.] [M

Fraz, Mitt. Natw. Ver. Mitteilungen des Naturwissenschaftlichen Steierm. Vereines für Steiermark. Red. v. C. Doelter. Graz. [jührl.]

Graz, Mitt. Steierm. Gar- Mitteilungen des k. k. Steiermärkischen tenbVer.

Graz, Mitt. Steierm. Gewb. Ver.

Graz, Mitt. Ver. Ärzte Steierm.

Graz, Pferdezüchter .. Gartenbau-Vereines. Graz. [monatl.] [M

Mitteilungen des Steiermärkischen Gewerberereines Graz. [1 monatl.]

Mitteilungen des Vereines der Ärzte in Steiermark. Graz. [9 H. jährl.] [OQR

Der Pferdezüchter. Organ des Steierischen Vereines zur Hebung der Pferdezucht. Graz. [monatl.]

GummiZtg, Wien .. . . Gummi-, Guttapercha-, Asbest- und ZelluloidZeitung. Wien. [ $\frac{1}{2}$ monatl.] [BD

Gut Licht, Wien .. . . Gut Licht. Zeitschrift für Amateurphoto. graphie und rerwandte Kunstzweige mit Berücksichtigung der Photographie. Herausgeg. v. Franz Sedlaczek. Wien. [monatl.] [BC

\section{H}

HdlAnz., Wien _. $\quad$.. $\quad$ Handelsanzeiger. Organ für Handel, Industrie; Assekuranz-, Bank-, Sparkassen- und Verkehrswesen. Herausgeg. v. S. Landesberg.

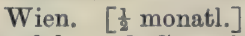

Hdl. GewbBl. Öst.Ung., Handel- und Gewerbeblatt für Österreich-Ungarn. Wien. [wöchentl.]

\section{6}


Hlas od Cidliny, Neubidschow

Hugos JagdZtg, Wien ..

Hund, Wien $\quad$.. $\quad .$.

Hundesport, Wien.. $\quad$..

IU. Flora, Wien .. . ..

Ill. MonBl. Bienenz., Klos. ternewburg

III. TierTogelfrd., Graz..

III. Tierfrd., Köflach

Imker, Prag .. ..

Industrie, Wien $\quad . . \quad$..

Innsbruck, Ber. Natw. Med. Ver.

Innsbruck, Mitt.Tir. GewbVer.

Tnusbruck, Zs. Ferd. ..

Intern. MinQuellZtg, Wien JägerZtg, Saaz .. ..
JahrBer, Verbd. Dachpapp.
TeerAsphaltInd.

Kanariensilchter, Wien ..
Hlas od Cidliny ..... Neubydžov. [Stimme vom Cidlina lusse. Anzeiger des Landwirtschaftlichen Vereines. Neubidschow. monatl.]

[DMN

A[lbert] Hugos Jagdzeitung. Red. v. Adolf

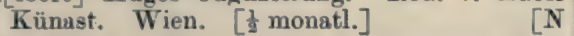

Der Hund. Unabhängige kynologische Zeitschrift für Österreich-Ungarn. Herausgeg. v.

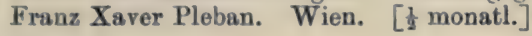
Herausgeg. v. Paul Gerin. Wien. [monal.].]

\section{I}

Illustrierte Flora. Fachzeitschrift für den gesamten Gartenbau. Red. v. Otto Pfeiffer. Wien. [monatl.]

[M

Illustrierte Monatsblätter für Bienenzucht. Zeitschrift für die Gesamtinteressen der Bienenwirte Österreichs. Herausgeg. u. red. v. Theodor Weippl. Klosterneuburg. [monatl.]

132

133

Illustrierte Zeitschrift für Tierfreunde. Organ des Österreichischen Bundes der Vogelfreunde in Graz ..... Graz. [monatl.] [N

Der Illustrierte Tierfreund. Herausgeber Max Pauly. Köflach. [monatl.]

$[\mathbf{N}$

Der Deutsche Imker aus Böhmen. Organ des Deutschen Bienenwirtschaftlichen Landeszentralvereines für Böhmen. Red. v. Hans Bassler. Prag. [monatl.] [N

Die Industrie. Organ für die Interessen der österreichischen Industrie. Wien. [wöchentl.]

Berichte des Naturwissenschaftlich-Medizinischen Vereines in Innsbruck. Innsbruck. [jährl:]

Mitteilungen des Tiroler Gewerbevereines. Innsbruck. [monatl.]

Zeitschrift des Ferdinandeums für Tirol und Vorarlberg. Innsbruck. [jährl.]

Internationsle Mineralquellen-Zeitung. Wien. [ monatl.]

\section{$J$}

Jägerzeitung für Böhmen und Mähren. Saaz. [t monat1.]

Jahresbericht des Verbandes der Dachpappe-, Teer- und Asphaltindustriellen in Österreich. Ungurn. Wien. [jährl.]

[BD

\section{K}

Erster Österreichisch-Ungarischer Kanarienzüchter. Fach. und Insertionsblatt für Kanarienzucht, Vogelschutz und Handel. Wien. [monatl.] 
KaninchenRdsch., Wien... Schwabs Kaninchen-Rundschau. Wien. $[\mathrm{N}$

Klagenfurt, Jahrb. Nat- Jahrbuch des Naturhistorischen LandesHist. I.dMus. Kürnten Museums von Kärnten. Red. v. Karl Frau. scher. Klagenfurt. [jährl.]

Kleintierzïchter, Wien .. Der Kleintierzüchter. Zeitschrift für die Gesamtinteressen der Kleintierzüchter. Wien. [monatl.]

145

146

147

KlinTherap. WochSchr., Klinısch-Therapeutische Wochenschrift, früher Wien „Therapeutische Wochenschrift.“ Herausgeg. und red. v. M. T. Schnirer. Wien. [wöchentl.]

[DQR

Klosterneuburg, Mitt.Chem. Mitteilungen über die Arbeiten der k. k. Physiol. Versstat. WeinObstbau Chemisch-Physiologischen Versuchsstation für Wein. und Obstbau zu Klosterneuburg bei Wien. Herausgeg. von Leonhard Roesler. Wien und Leipzig. [zrvanglos.]

Klosterneuburg, Mitt.Gähr. Phys. Labor.

Mitteilungen aus dem Grährungsphysiologischen Laboratorium der k. k. Chemisch-Physiologischen Versuchsstation für Wein - und Obstbau in Klosternenburg bei Wien. Klosterneuburg. [zwanglos.]

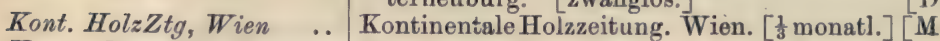
Krems, Mitt. Ver. Weinbau Mitteilungen des Vereines zum Schutze des österreichischen Weinbaues. Red. v. Ferd. Reckendorfer. Krems. [monatl.] [M

Kultur, Wien .. .. Die Kultur. Zeitschrift für Wissenschaft, Literatur und Kunst. Herausgegeben von der Österreichischen Leo-Gesellschaft. Wien u. München. [8 H. jährl.]

\section{L}

Laibach, Izv. Muz. Društ. Kranjsko

Izvestja Muzejskega Društva za Kranjsko. Urejuje Anton Kublar. V Ljublijani. Mitteilungen des Museal-Vereines für Krain. Laibach, 2 monatl.]

Laibach, Mitt. LandwGes. Mitteilungen der k. k. Landwirtschafts-GesellKrain schaft für Krain and deren selbständigen Sektionen für Pferdezucht und Fischerei. Laibach. [monatl.]

Laibach, Mitt. MusVer. Mitteilungen des Museal-Vereines für Krain. Krain Red. v. Oskar Gratzy Edlen von Wardengg. Laibach. [2 monatl.]

Laibach, Plan. Vestn. .. Planinski Vestnik. Glasilo Slovenskega Planinskega Društva. Luibach. [Berganzeiger. Organ des Slovenischen Touristenkluhs, monatl.]

LandForstw. UnterrZtg, Land- und Forstwirtschaftliche CnterrichtsWien Zeitung. Redigiert im Auftrage des k. $k$. Ackerbau-Ministeriums von Friedrich Ritter von Zimmerauer. Wien. [ $\frac{1}{4}$ jährl.] [DMN

LandVolkswirt.Mitt., Linz Land- und Volkswirtschaftliche Mitteilungen. Organ des Landeskulturrates für das Erzherzogtum Österreich ob der Enns. Red. v. Konstantin Werkowitsch. Linz. [ $\frac{1}{2}$ monatl. $]$

DMN

Landw. Mitt., Böhmisch- Landwirtschaftliche Mitteilungen. Organ der Leipa

land- und forstwirt schaftlichen Bezirksvereine von Leipa, Dauba, Gabel und Friedland.

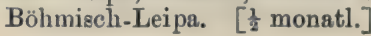

[DMN 
Landw. Mitt., Friedland.. Landwirtschaftliche Mitteilungen. Vereineblatt der land- und forstwirtschaftlichen Bezirks. vereine von Friedland, Gabel und Reichenberg. Friedland. [monatl.]

[DMN

Landw. Mitt. Kärnten, Landwirtschaftliche Mitteilungen für Kärnten. Klagenfurt Herausgegeben von der k. k. Landwirtschaftsgesellschaft. Red. v. Alfred Kohlert. Klagenfurt. [ 2 wöchentl. $]$

[DMN

Landw.Zs. ObÖsterr., Linz Landwirtschaftliche Zeitschrift für Oberösterreich. Organ der k. k. Oberösterreichischen Landwirtschafts-Gesellschaft. Linz. [t monatl.]

[DMN

Landw. Zs. ÖstSchles., Landwirtschaftliche Zeitschriłt für Österreich. Troppass $\quad$ Schlesien. Organ der k. k. ÖsterreichischSchlesischen Land- und ForstwirtschaftsGesellschaft. Red. v. Gustav Müller. Troppau. [ $\frac{1}{2}$ monatl.]

Landv. Zs. Sudeten, Landwirtschaftliche Zeitschrift ,Die Sudeten.“ Freivaldau

Monatliche Mitteilungen des Land- und Forstwirtschaftlichen Vereins für das Nordwestliche Schlesien. Red. v. A. Kulisz. Oberhermsdorf. Druck in Freiwaldau. [monutl.]

[DMN

Landv. Zs., Wien

Landwirtschaftliche Zeitschrift. Herausgegeben von der k. k. Landwirtschafts-Gesellschaft in Wien. Red. v. Josef Häusler. Wien. [ $\frac{1}{2}$ monatl.]

[DMN

Landw. Ztg, Wies _. Wiener Landwirtschaftliche Zeitung. Illustrierte Zeitung für die gesamte Landwirt. schaft. Herausgeg. v. Hugo H. Hitschmann. Wien, [t wöchentl.]

[DMN

Leitmeritz, JahrBer. Jahresbericht über die Tätigkeit der LandwirtLandw Chem. Unters. Stat. schaftlich-Chemischen Untersuchungs- und Samenkontrollstation der Ackerbau-, Obstund Weinbatisehule in Leitmeritz. Leitmeritz. [jährl.]

DM

Lékárn. Rozhl., Prag ..

Lékárnické Rozhledy. Zpravy ..... Praha. [Medizinische Revue. Berichte über die neuesten Fortschritte auf dem Gebiete der Praktischen Medizin. Prag, $\frac{1}{2}$ monatl.] [OQR

Lemberg, Zbirn. Sekc. MatPrirod Likarsk

Zbirnik Sekcii Matematično - PrírodopísnoLikarskoj ...... [Sammelschrift der Mathematisch - Naturwissenschaftlich - Ärztlichen Sektion der Ševčenko-Gesellschaft der Wissenschaften in Lemberg. Lemberg.]

Leoben, Berg. Hïttenm. Berg- und Hüttenmännisches Jahrbuch der k. Jahrb.

k. Bergakademien zu Leoben und Přibram uncl der Königlich Ungarischen Bergakademie zu Schemnitz. Red. v. Hans Höfer u. C. v. Ernst. Wien. [t jahrl.] [DBGH

Lid. Rozpr. Lékar̃., Prag Lidové Rozpravy Lékařské. Porádá Ladislav Haškovec. Praha. [Populäre Medizinische Abhandlungen. Herausgeg. v. Ladislaus Haškovec. Prag, zwanglos.] [OQR

Linz, JahrBer. Mus. Jahresbericht des Museums Francisco-Carolinum. Nebst der.... Lieferung der Beiträge zur Landeskunde von Österreich ob der Enns. Linz. [jährl.]

Lins, JahrBer. Ver. Jahresbericht des Vereines für Naturkunde in Natkdo

Oesterreich ob der Enns zu Linz. Linz. [jährl.] 
Listy Chem., Prag _. Listy Chemické. Organ Chemické Společnosti :

Spolek Chemicků Českých. Red. J. Mašín, E. Votoček. Praha. [Chemische Blätter. Organ des Vereines Tschechischer Chemiker. $[10 \mathrm{H}$. jährl.]

Listy Cukrovarn., Prag .. Listy Cukrovarnické. Praha. [Blätter für Zuckerindustrie. Prag, $\frac{1}{3}$ monatl.] [BD

Listy Zahradn., Prag .. Listy Zahradnické. Illustrovaný Časopis . . . . . Praha. [Blätter für Gärtner. Illustrierte Zeitschrift für die Interessen der Baumzucht, des Weinbaues etc. Prag, monatl.]

Litografia, Prag .. $\quad$.. Litografia. Orgán pro Litografii, Kamenotisk, Grafická Umění a Spřibuzněná Odvětvi. Praha. [Lithographie. Organ für Lithographie, steindruck, Graphische Künste und verwandte $Z$ weige. Prag, 辛 monatl. $] \quad[\mathrm{BD}$

LuftschiffrZtg, Wien .. Wiener Luftschiffer-Zeitung. Unabhängiges Fachblatt für Luftschiffahrt und Fliegekunst, sowie die dazu gehörigen Wissenschaften und Gewerbe. Herausg. v. Victor Silberer. Wien. [monatl.]

Lussinpiccolo, Astr. Rdsch. Astronomische Rundschau. Herausgegeben von der Manora - Sternwarte in Lussinpiccolo [Österreich]. Red. v. Leo Brenner. Lussinpiccolo. [10 H. jährl.]

[EF

\section{M}

Mähr. GewZtg, Brünn .. Mährische Gewerbe-Zeitung. Neue Folge der Vereinszeitschriften Das Kleingewerbe und Mährisches Gewerbeblatt. Herausgegeben vom Mährischen Gewerbevereine in Brünn.

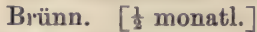

MährSchles. GewbZtg, Ol- Mährisch-Schlesische Gewerbe-Zeitung. Olmütz. mütz [monatl.]

MährSchles. Ind. HdlBl., Mährisch-Schlesisches Industrie- und HandelsOlmuitz blatt. Herausg. u. red. v. Max Hoenig. Olmütz. [monatl.]

Malzindustrie, Wien _. Die Malzindustrie. Zentralorgan der österreichischen Malzindustriellen. Red. v. Adolf Sehwarz. Wien. [monatl.] [BD

Marchfeldkultur, Wien .. Marchfeldkultur. Agrar-politische Monatsschrift, besonders für die national-ökonomischen Interessen der Reichshauptstadt Wien und des Marchfeldes. Red. v. J. E. Mitten. dorfer. Wien. [monatl.] [DMN

Masch. MetallindZtg,Wien Maschinen- und Metallindustrie-Zeitung. Wien. [2 wöchentl.]

Med.Bl., Wien .. . .. Medizinische Blätter. Wochenschrift für die gesamte Heilkunde. Red. v. Max Neuburger. Wien. [wöchentl.] [OQR

MedChir. ZentrBl., Wien

Medizinisch-Chirurgisches Zentralblatt. Organ der praktischen Ärzte. Red. v. J. Segel. Wien. [wöchentl.] [OQR

Met. Zs., Wien .. . . Meteorologische Zeitschrift. Herausgegeben im Auftrage der Österreichischen Gesellschaft für Meteorologie und der Deutschen Meteorologischen Gesellschaft. Red. v. J[ulius] Hann und G[ustav] Hellmann. Zugleich Zeitschrift der Österreichischen Gesellschaft für Moteurologio. Wien. [monatl.] 
Metallarbeiter, Wien .. Der Metallurbeiter. Fachblatt für die gesamte 190 Eisen-, Metall-, Maschinen-, Montanindustrie etc. Red. v. Ludwig Vidéky. Wien. [wöchentl.] [B

Metallindustrie, Wien .. Metall-Industrie. Wien. [2 monatl.] [B MilitÄrztl. Publ., Wien.. Militärärztliche Publikationen. Wien. $\left[\frac{1}{4}\right.$ 191 1.92

Min. Petr. Mitt., Wien .. Tschermaks Mineralogische und Petrographische Mitteilungen. Herausgeg. v. F[riedrich] Becke. Wien. [2 monatl.]

Mitt. Artill. Geniew., Wien Mitteilungen über Gegenstände des Artillerieund Geniewesens. Herausgegeben vom k. u. k. Technischen Militärkomitee. Wien. [monatl.]

Mitt. Forstl. VersWesen Mitteilungen aus dem forstlichen VerzuchsÖst., Wien wesen Österreichs. Wien. [M Mitt. Gartenb. Geflüg. Mitteilungen über Gartenbau, Geflügel- und BienZucht, Linz

Mitt. Geb. Feuerlöschw., Weipert Bienenzucht. Linz. [monatl.] [DMN Mitteilungen auf dem Gebiete des Feuerlöschwesens. Organ des Feuerwehr-Landes-Zentral-Verbandes für Böhmen. Geleitet von

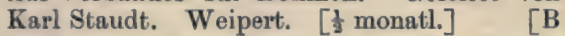

Mitt. LandForstHaus- Mitteilungen über Gegenstände der Land-, voirtsch., Klagenfurt Forst- und Hauswirtschaft. Klagenfurt. [t monatl.] [DMN

Mitt. Nordböhm. ExkKlub, Mitteilungen des Nordböbmischen ExkursionsBöhmisch-Leipa

Mitt. Öst. Liqu. Spir. Mitteilungen des Verbandes Österreichischer EssigFabr., Brünn Liqueur-, Spirituosen- und Essigfabrikanten. Brünn. [monatl.] [BD

Mitt. SchnalspurBranche, Mitteilungen aus der Schmalspurbranche. Red. Wien

v. Koessemaun und Kühnemann. Wien.

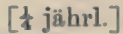

Mitt. Sekt. Ld. Forst- Mitteilungen über die Verhandlungen der Sekwirtseh., Wien tion für Land- und Forstwirtschaft und Montanwesen des Industrie- und Landwirtschafts. rates. Wien.

[DMN

Mitt. Ver. Förd. Lok- Mitteilungen des Vereines für die Förderung des Strassenbahno., Wien Lokal- und Strassentahnwesens. Wien. [monatl.]

Mod. BeleuchtWesen, Wien Das Moderne Beleuchtungswesen. Umschau suf dem Grebiete der Lichterzeugung und Lichtversorgung aller Länder der Welt. Red. v. Franz Kleinpeter. Wien.

Mödling, Milt. Ver. Nat- Mitteilungen des Vereines der Naturfreunde in Frde.

Mödling. Mödling. [zwanglos.]

MonBer. Obst Wein Gart. Monatsbericht. Fachorgan des Deutschen Obst-, Ban, Brïnn Wein- und Gartenbauvereines für die Markgrafachaft Mähren. Red. v. Leopold Kr̆iwanek. Brünn. [monatl.] [M

MonHfte Math. Phys., Monatshefte für Mathematik und Physik. Mit Wien Unterstützung des hohen k. k. Ministeriums für Kultus und Unterricht herausgegeben von G[ustav] v[on] Escherich und L[eopold] Gregenbauer. Wien. [zwanglos.] [ABC

MonSchr. GesundhPflege, Monatsschrift für Gesundheitspflege. Organ Wien der Österreichischen Gesellschaft für Gesund. heitspflege. Red. v. Heinrich Adler. Wien. [monatl.] 
MonSchr. Kinderheilkde., Monatsschrift für Kinderheilkunde .... Red. Wien

MontZtg Öst. Ung., Graz. v. Arthur Keller. Wien und Leipzig. $\quad[\mathrm{OQR}$ Montan-Zeitung für Österreich-Ungarn, die Balkanländer und das Deutsche Reich. Fachorgan für Berg-, Hütten- und Salinenwesen ..... Herausgeg. v. Franz H.

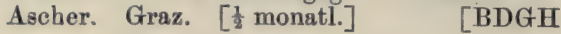

Naše Doba, Prag .. .. Naše Doba. Revue pro Vědu, Jmění a Život Sociální. Praha. [Unsere Zeit. Revue für Wissenschaft, Kunst und Soziales Leben. Prag, monatl.]

NationÖkom., Wien _. Der Nationalökonom. Zeitschrift für Volkswirt-

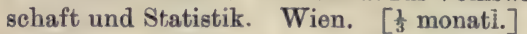

Natürl.Heilmethoden,Wien Natürlichere Heilmethoden. Organ für praktische Hygiene, Hydro-, Photo- und Thermotherapie, etc. Herausgeg. u. red. v. Karl Georg Panesch. Wien. [zwanglos.] [DQR

Naturarzt, Wien .. $\quad$.. $\quad$ Der Naturarzt. Organ des Ersten Wiener Naturheilvereines. Wien [OQR

Naut. Rdsch., Wien .. Nautische Rundschau. Österreichische Zeitschrift für See- und Binnenschiffahrt. Wien [t monatl.]

Neue Graph. Nachr., Wien

Neue Graphische Nachrichten. Herausgeg. $u$.

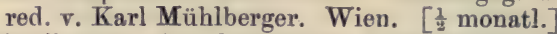

Neutitschein, Mitt. Kuhl. Mitteilungen des Kuhländer LandwirtschaftLandw. Ver. lichen Vereines Neutitschein. Red. v. Heinrich Maresch. Zauchtel. [monatl.]

DMMN

NiedÖst. LdFrd, Baden...

Der Niederösterreichische Landesfreund. Blätter zur Laudeskunde. In zwanglosen Nummern herausgegeben von der Tischgesellschaft "Niederösterreichische Landesfreunde " in Baden bei Wien. Red. v. Karl Coiliano. Baden. [monatl.]

Nordböhm. Landw. Mitt., Schluckenau

Nordböhmische Landwirtschaftliche Mitteilungen. Organ des Land- und Forstwirtschaftlichen Vereinsverbandes für Nordböhmen. Schluckenau. [monatl.] [DMN

Nov. HájLověna, Tabor .. Nový Háj a Lověna. Lesnický a Lovecký Č́asopis pro Majitele a Spráry Lesů, Lesníky, Myslivce, Př́tele Lovu a Př́rndy. Vexstnik Lesnických Ustarů v Písku. Red. Iad. Burket . . . . Tábor [Neuer Hain und Jagd. Forst- und Jagdzeitung für Waldbesitzer und Verwalter, für Forstleute, Jäger, Jagd- und Naturfreunde. Anzeigeblatt der Forstanstalt in Pisch. Tabor, monatl.] [M

Nste ErdbebNachr., Tai- Neueste Erdbeben-Nachrichten. Herausgeg. v. bach

A. Belar. Beilage der Monatsschrift, Die Erdbebenwarte." Laibach. [zwanglos.] [H

Nste Erfdgn Prakt. Techn., Neueste Erfindungen und Erfahrungen auf den Wien Gebieten der praktischen Technik, Elektrotechnik, der Gewerbe, Industrie, Chemie, der Land- und Hauswirtschaft. Herausg. v. Theodor Koller. Wien. [13 H. jährl.] 
Nster Forst Jagd JahrBer., Neuester Forst- und Jagd-Jahresbericht über Eger. wichtigere Vorkommnisse und Veröffentlichungen, beziehungsweise erprobte Fortsohritte, sowie bewährte Erfahrungen beim Forst- und Jagdwesen samt Holzhandelsnachrichten. Eger-Franzensbad.

Obstgarten, Klosternewburg

Obstzïchter

Scheibbs

Obstzüchter, Krems

Obzor Národohosp., Prag..

Okonon, Wien .. . .

O̊st. Ärztl. VerZtg, Wien

Ont. Alpenpost, Innsbruck

Öst. Bot. Zs., Wien

Öst. Brau HopfZtg, Prag. . Öst. ChemZtg, Wien

Ǒt. EisenbZtg, Wien ..

Ort. FavblackZtg, Wien. . Ost. ForstJagdb1., Bribnn

Der Obstgarten. Zeitschrift für Obst- und Gartenbau. Herausgeg. ₹. A. Freih[errn] $\mathrm{v}$ [on] Babo. Red. v. Fr. Š́cha. Klosterneu. burg. [monatl.]

Der Praktische Obstzüchter aus dem Erlaftale. Scheibbs. [monatl.]

Der Obstrüchter. Krems. [monatl.] [

Obzor Národohospodářský. Časopis věnovaný otázkám Národuhospodářským a Suciálnĕpolitickým. Orgán Jednoty ku Povzbuzení Prümyslu v Čechách a Vývozního Spolku pro Čechy, Moravu a Slezsko. Red. Josef Gruber. Praha. [Volkswirtschaftliche Rundschau. Zeitschrift für Volkswirtschaft und Sozialpolitik. Organ der Gresellschaft zur Hebung der Industrie in Böhmen und des Exportvereines für Böhmen, Mähren und Schlesien. Prag, t monatl.]

Der Ökonom. Illustrierte Landwirtschaftliche Zeitung. Herausgeg. v. Hugo H. Hitschmann.

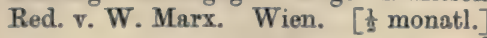

[DMN Osterreichische Arztliche Vereinszeitung. Organ für ärztliches Vereinswesen und öffentliche

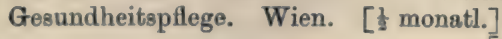

[OQR Österreichische Alpenpost. Illustrierte Zeitung aus den Ostalpen. Herausgeg. v. A. Koppelstätter, red. v. J. C. Platter und Paul R. Greussing. Innsbruck-Wilten. [ [ monatl.]

Osterreichische Botanische Zeitschrift. Heraus. geg. u. red. v. Richard R[itter] Wettstein $\mathbf{v}[$ on Westersheim $]$. Wien. [monatl.] [M

Österreichische Brauer- und Hopfen-Zeitung. Prag. [t monatl.]

Österreichische Chemiker-Zeitung. (Vorınals Zeitachrift für Nahrungsmittel-Untersuchung, Hygiene und Waarenkunde.) Herausg. v. Hans Heger u. Eduard Stiassny. Wien. [ $\frac{1}{d}$ monatl.]

Österreichische Eisenbahn-Zeitung. Organ des Klubs Österreichischer Eisenbahnbeamten. Wien. [36 H. jährl.]

[B

isterreichische Furben- und Lack-Zeitung. Organ für die gesamte Farben-, Lack- und Firnisfabrikation, sowie mit dieser in Verbindung stehende Industrien, Handel und Gewerbe. Wien. [t monatl.] [BD Österreichisches Forat- und Jagdblatt ... Red. v. K. Wibirnl. Brinnn. [2 wöchentl.] [M 
Öst. ForstJagdZtg, Wien.. Österreichische Forst- und Jagdzeitung. 「Illustriertes Wochenblatt für Forstwirtschaft und Holzhandel, Holzindustrie, Jagd und Fischerei. Herausgeg. v. Hugo H. Hitschmann. Red. v. Jos[ef] E. Weinelt. Wien. [wöchentl.]

[M

Öst. Jahresh. Pharmaz., Österreichische Jahreshefte für Pharmazie und Wien verwandte Wissenszweige. Gesammelte $\mathrm{Ab}$ handlungen und Vorträge aus der Zeitschrift des Allgemeinen Österreichischen Apothekervereines. Wien. [jährl.]

[DQ

Öst. Landw. WochBl., Wien Österreichisches Landwirtschaftliches Wochenblatt. Red. v. Guido Krafft. Wien. [wöchentl.]

Öst. Mil. Zs., Wien _. Streffleurs Österreichische Militärische Zeitschrift. Red. v. Viktor Grzesicki. Wien. [monatl.] [BCD

Öst. MolkZtg, Wien .. Österreichische Molkerei-Zeitung. Red. v. Leopold Adametz und Willihald Winkler. Wien. [ $\frac{1}{2}$ monatl.] [DMN

Öst. MonSchr. Orient, Wien Österreichische Monatsschrift für den Orient. Verlag des k. k. Öster[reichischen] HandelsMuseums. Wien. [monatl.]

Óst. MonSchr. Tier- Österreichische Monatsschrift für Tierheilkunde heilkde, Wien $\quad$ und Revue für Tierheilkunde und Tierzucht. Herausgeg. u. red. v. Alois Koch. Wien. [monatl.] [DNQ

Öst. MoorZs., Staab _. Österreichische Moorzeitschrift. Monatshefte des Deutschösterreichischen Moorvereines. Red. v. Hans Schreiber. Staab. [monatl.]

Öst. Rev. Assek., Wien ..

Öst. SanitWesen, Wien ..

Öst. VersichZtg, Wien ..

Öst. VierteljSchr. Forstw., Wien

Öst. Weingarten, Klosterneuburg

Öst. WirtschPol. Arch.,
Wien

Öst. Wochschr. Öffentl. Baudienst, Wien
Österreichische Revue. Organ für Assekuranz und Volkswirtschaft. Herausgeg. v. S. Löwen. berg. Wien. [wöchentl.]

Das Ớsterreichische Sanitätswesen. Organ für die Publikationen des k. k. Obersten Sanitätsrates. Red. r. J. Daimer und F. Stadler. Wien. [wöchentl.] [DQR Österreichische Versicherungszeitung. Wien. [wöchentl.]

Österreichische Vierteljahrsschrift für Forstwesen. Herausgegeben rom Österreichischen Reichsforstvereine. Red. v. Adolf Ritter von Guttenberg. Wien. [ $\frac{1}{4}$ jährl. $]$

[M

Der österreichische Weingarten. Halbmonatsschrift für die Interessen des österreichischen Weinbaues, für Weinhandel, Kellertechuik und die gesamte Landwirtschaft. Red. v. Julius Oberhuber. Klosterneuburg. [ $\frac{1}{2}$ monatl.]

Österreichisches Wirtschaftspolitisches Archiv (vormals ,, Austria "). Redigiert und herausgegeben rom k. k. Handelsministerium. Wien. [zwanglos.]

Österreichische Wochenschrift für den öffentlichen Baudienst. Amtliches Fachblatt, herausgegeben von den k. k. Ministerien des Innern, der Finanzen, des Handels, der Eisenbahnen und des Ackerbaues. Chef-Red. Alfred Ritter Weber von Ebenhof. Wien. [wöchentl.] 
Öst. Woll. LeinInd., Reich - Österreichs Wollen- und Leinenindustrie. Zeitenberg schrift für die gesamte Wollen-, Baumwollen-, Jute-, Ramie-, Leinen- und Seidenindustrie nebst den bezüglichen Geschäftsbranchen. Red. v. W. F. Profeld. Reichenberg. [t monatl.]

Ost. Zs. BergH ïttWes., Österreichische Zeitschrift für Berg- und HütWien

tenwesen. Red. v. Friedrich Toldt und K[arl Ritter]. v. Ernst. Wien. [wöchentl.]

[BDGH

Öst. Zs. Stomat., Wien ..

Österseichische Zeitschrift für Stomatulogie. Organ für die wissenschaftlichen und Standesinteressen der Zahnärzte Österreichs. Hersusgeber: Zentralverband der Österreichischen Stomatologen. Red. v. Hugo Trebitsch und Rudolf Vierthaler. Wien. [monatl.] [OQ

Öst Ung. AntomobZtg, Wien Österreichische und Ungarische AutomobilZeitung. Wien. [monatl.]

ÖstUng. BienenZtg, Wien

Österreichisch-Ungarische Bienenzeitung. Wien. [monatl.]

OstUng. Eisenb Bl., Wien

Österreichisch-Ungarisches Eisenbahnblatt. Urgan für das gesamte Verkehrswesen. Herausg. v. J. Schwarz. Wien. [wöchentl.]

ÖstUng. Graph. ZentrBl., Österreichisch-Ungarisches Graphisches ZentralWien blatt für Buch- und Steindruckereien, Lithographien und verwandte Geschäfte. Herausgegeben von Alexander Schwartz. Wien. [ monatl.]

Öst Ung. LdrBl., Wien .. Österreichisch-Ungarisches Leder-Blatt. Herausg. v. S. Käs. Wien. [8 tägl.] [BD

ÖstUng. Müller, Wien .. Der Österreichisch-Ungarische Müller. Monatsschrift zur Verbreitung nützlicher Kenntnisse in der Müllerei, Bäckerei und verwandten Geschäftszweigen. Herausgeg. v. Rudolf Masss. Wien. [monatl.]

Ost Ung. Rev., Wien _. Österreichisch-Ungarische Revue. Monats. schrift für die gesamten Kultur-Interessen der Österreichisch-Ungarischen Monarchie. Herausgeg. u. red. v. A. Mayer-Wyde. Wien. [monatl.]

Ost $C_{n g}$. TextilInd., Rei- DerÖsterreichisch-Ungarische Textilindustrielle. chenberg

OstUng. UhrmZtg, Wien. . Reichenberg. [monatl.]

[BD

Österreichisch-Ungarische Uhrmacher-Zeitung. Red.v. Josef Flamm. Wien. [monatl.] [B

Got Ung. VierteljSchr. Zahnheilkde, Wien

Österreichisch- Tngarische Vierteljahrsschrift für Zahnheilkunde. Herauggeg. v. Julius Weiss. Wien. [1 jührl.]

Ost Ung. ZentrBl. Med. Wiss., Wien

Österreichisch - Ungarisches Zentralblatt für die Medizinischen Wissenschaften. Wien. [worchentl.]

OstUrg. ZentrBl. Wald. erz., Wien

Österpioin [OQR Walderzeugnisse, Organ für Holahandel Forst- und Eichenschälwirtschaft. Red. v. M. Strassberger. Wien. [wöchentl.] [M

OstUng. Zs. Zuckerind. Österreichisch. Ungarische Zeitschrift für Landw., Wien

Zuckerindustrie und Landwirtschaft. Red. จ. Friedrich Strohmer. Wien. [2 monatl.]

OstUng.Zindw Fblt.,Hořo. Österreichisch - Ungarischer Zündwarenfabrisoitz

kant. Organ für alle Fächer der Zündwarenfabrikation. Ho:̌owitz. [monatl.]

[BD 
Olmütz, Čas. Muz. Spolku

Org. MilWiss. Ver., Wien

Ornith. Jahrb., Hallein ..

Pap. SchreibwZtg, Wien..

Parenzo, AttiSoc. Istr. Arch.

Pharmaz. Post, Wien ..

Pharmaz. Praxis, Wien ..

Pharmaz. Rdsch., Wien ..

Pharmaz. Reformer, Wien

Pils. Landw. Ztg, Pilsen. .

Pilsen, Arb. Chir. Sanat. Jaklin

Pola, Mitt. Geb. Seew. ..

Post u. Telegraph, Wien..

PostTel. VerordBl., Wien
Časupis Vlasteneckého Spolku Muzejního $\boldsymbol{v}$ Olomouvi. Olomouc. [Zeitschrift des Vaterländischen Musealvereins in Olmütz. Ol-

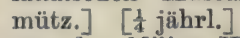

Organ der Militär-Wissenschaftlichen Vereine. Herausgegeben rom Ausschusse des MilitärWissenschaftichen Vereines in Wien. Wien. [zwanglos.]

Ornithologisches Juhrbuch. Organ für das paläarktische Faunengebiet. Herausgeg. v. Viktor Ritter von Tschusi zu Schmidhoffen. Hallein. [2 monatl.]

\section{$\mathbf{P}$}

Papier- und Schreihwaren-Zeitung. Fachorgan für Papier- und Schreibwaarenhandel und

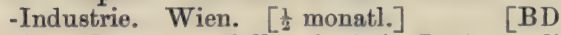

Atti a Memorie della Sucietà Istriana di Archeologia e Storia Patria. Parenzo. [trimestr.]

Plıarmazeutische Post. Wochenschrift für die gesamten Interessen der Pharmazie. Offizielles Organ der Österr. Pharmazeutischen Gesellschaft. Herausgeg. v. Hans Heger. Wien. [wöchentl.]

[DQ

Pharnazeutische Praxis. Zeitschrift für die wissenschaftliche und praktische Pharmazie der Gegenwart und die verwandten Fächer. Herausgeg. u.gel. v. Josef Longinovits. Wien und Leipzig. [monatl.] [DQ

Pharmazeutische Rundschau. Wochenschrift für die Interessen der Pharmazie, Chemie, Hygiene und der verwandten Fächer. Organ des , Verbandes deutscher Apotheker in Böhmen," des ,, Vereines der Landapotheker Niederösterreichs"....W Wien. [wöchentl.] $[\mathrm{DQ}$

Pharmazeutischer Reformer. Zeitschrift für die wissenchaftlichen und gewerblichen Interessen der Pharmazie. Organ des Verbandes pharmazeutischer Vereine Österreichs. Herausgeg. vom Allg. Österr. Pharmazeutenverein. Wien. [wöchentl.] [DQ

Plzeňské Hospodářské Noviny. Plzeñ. [Pilsener Landwirtschaftliche Zeitung. Pilsen, $\frac{1}{2}$ monatl.]

[DMN

Arbeiten aus dem Chirurgischen Sanatorium Dr. Jaklin in Pilsen. Pilsen. [ $\frac{1}{4}$ jährl.] [OQ Mitteilungen aus dem Gebiete des Seewesens. Herausgegeben vom k. u. k. Marine-Technischen Komitee. Pols, [monatl.]

Post und Telegraph. Fachorgan für das Postund Telegraphen-, das Eisenbahn- und Schifffahrts- sowie das gesamte Speditions- und Verkehrswesen. Herausgeg. v. G. Ad. UngárSzentmiklósy. Wien, [2 wöchentl.] [BC Post- und Telegraphen- Verordnungsblatt für das. Verwaltungsgebiet des k. k. Handelsministeriums: Wien. [zwanglos.] [BC 
Prag, Abh. Böhm. Ges. Abhundlungen der Mathematisch-Naturwissen$W$ iss. schaftlichen Klasse der Königlich Böhmischen Gesellschaft der Wissenschaften. Prag. [zwanglos]

Prag, Abh.Lotos.. . . Abhrndlungen des Deutschen Naturwissenschaftlich - Medizinischen Vereines für Böhmen "Lotos." Prag. [zwanglos.]

Prag, Alman. České $A k$. Almanach České Akademie Císaře Františka Frant. Jos. Jcsefa pro Vědy, Slozesnost a Uměni. Praha. [Almanach der Tschechischen Kaiser Franz Josef8-Akademie für Wissenschaft, Literatur und Kunst.]

Prag, Archit. Obzor .. Architektonický Obzor. Orgán Spolku Architektův a Inženýrů v Království Č́eském. Red. A. Balæ̌́nek. Praha. [Architektonische Rundschau. Organ des Vereinez der Architekten und Ingenieure im Königreiche Böhmen]. [t monatl.] [B

Prag, Ber. Mus. Böhmen..

Bericht über das Museum đes Königreiches Böhmen. Prag. [jährl.]

Prag, Ber. VersAnst. BrauInd. Böhmen

Bericht über die Tätigkeit der Versuchsanstalt für Brauindustrie in Böhmen zu Prag. Wien.

[BD

Prag, Bull. Ac. Sci. Franç. Jos.

Académie des Sciences de l'Empereur François Joseph I. Bulletin International. Prag.

Prag, C̆as. Math. Fys. . . Časopis pro Pěstováni Mathematiky a Fysiky. Red. Augustin Pánek a vydává Jednota Českých Mathematiki̊. Praha. [Zeitschrift zur Pflege der Mathematik and Physik. Herausgegeben vom Vereine Tschechischer Prag, Čas. Mus. Česk. .. Časopis Musea Králorstrí Českého. $\begin{gathered}\text { Mathemaliker } \\ \text { Red. }\end{gathered}$ Frant[ǐ̌ek] Krapil, Čeněk Zíbrt. Praha. [Zeitschrift des Museums des Königreiches

Prag, Čas. Spol. Přát. Časopis Společnosti Př́tel Starožitností Českých Starožitn. Česk. $\quad$ v Praze. Praha. [Zeitschrift der Gesellschaft Tschechiecher Altertumsfreunde in Prag, $\frac{1}{4}$ jährl.]

Prag, Fotogr. Obzor .. Fotografický Obzor. Orgán Českého Klubu Fotografủ-Amatérů v Praze. Red. Frantisek Dvoŕk. Praha. [Photographische Rundschau. Organ des Tschechischen Klubs der Amateur-Photographen in Prag, monall.] [BC

Prag, JahrBer. Böhm. Ges. Wiss.

Jahreshericht der Kön[iglich] Böhmischen Gresellschaft der Wissenschaften. Prag. [jährl.]

Prag, LdForstw. Mitt. .. Land- und Forstwirtschaftliche Mitteilungen. Amtliche Verlautbarungen der Deutschen Sektion des Landeskulturrates für das Königreich Bőhmen. Prag. [DMN

Prag, II Lék. Klin. . . Z II. Lékařské Kliniky. Klinické Práce a Vdělení. Uveřejňuje Emerich Maixner. Praha. [A us der II. Medizinischen Klinik. Klinische Arbeiten. Prag.] [zwanglos] [OQK

Prag, Med. Wochschr. .. Prager Medizinische Wochenschrift. Amtliche Zeitschrift der Deutschen Sektion der Ärztekammer für das Königreich Böhmen..... Red.v. Ludwig Waelsch. Prag. [wöchentl.] 
Prag, Mitt. Ges. Förd. Dtsch. Wiss. Böhmen

Prag, Mitt. Stat. LdAmt Böhmen

Prag, Národop. Sborn. Čskoslov.

Prag, Pam. Arch. Mistop.

Prag, Rozpr. České Ak. Frant. Jos.

Prag, Samml. Gemeinnütz. Vorträge

Prag, Sborn. Jedn. Česk. Math.

Prag, SitzBer. Böhm. Ges. Wiss.

Prag, SitzBer. Lotos _.

Prag, Techn. Bl. .. ..

Prag, Techn. Obzor ～..

Prag, Trav. Géogr. Tchè. ques

Prag, Verh. Dtsch. Sekt. Arztekamm. Böhmen
Mitteilungen der Gesellschaft zur Förderung Deutscher Wissenschaft, Kunst und Literatur in Böhmen. Prag.

Mitteilungen des Statistischen Landesamtes des Königreiches Böhmen. Deutsche Ausgabe. Prag. [zwanglos.]

Národopisný Sborník Českoslovanský. Vydává Národopisna Společnost Českoslovanská a Národopisné Museum Českoslovanské. Red. Jiří Polívka. Praha. [Magazin für Tschechoslavische Volkskunde. Herausgegeben vom Museum für Tschechloslavische Volkskunde, jährl.]

Památky drchaeologické a Místopisné. Organ Archaeologické Komise při Časké Akademii Císaře Františka Josefa pro Vědy, Slovesnost a Umění a Archaeologického Sboru Musea Království Českého. Red. Josef $\operatorname{Lad}$ [islav] Pič. Praha. [Archäologische und Topographische Denkmäler. Organ der Archäologischen Kommission der Tschechischen Kaiser Franz Josefs-Akademie für Wissenschaft, Literatur und Kunst und des Archäologischen Musealvereines für das Königreich Böhmen. Prag, $\frac{1}{4}$ jährl.]

Rozpravy České Airademie Císaře Františka Josefa pro V̋̀dy, Slovesnost a Umění. Praha. [Abhandlungen der Tschechischen Kaiser Franz Josefs-Akademie für Wissenschaft, Literatur und Kunst]. [zwanglos]

Sammlung Gemeinnütziger Vorträge. Herausgegeben vom Deutschen Vereine zur Verbreitung Gemeinnütziger Kenntnisse in Prag. [zwanglos]

Sborník Jednoty Českých Mathematiků $\nabla$ Praze. Praha. [Magazin des Vereines Tschechischer Mathematiker in Prag.]

Sitzungsberichte der Königlich Böhmischen Gesellschaft der Wissenschaften. Mathemati-ch-Naturwissenschaftliche Klasse. Prag. [jährl.]

Sitzungsberichte des Deutechen Naturwissenschaftlich-Medizinischen Vereines für Böhmen ", Lotos " in Prag. Prag. [jährl.]

Technische Blätter. Vierteljahrsschrift des Deutschen Polytechnischen Vereines in Böhmen. Red. v. Franz Stark. Prag. [ $\frac{1}{4}$ jährl.]

Technický Obzor. Orgán Spolku Architekůva Inženýrů マ Království Českém. Red. J. Lhota. Praha. [Technische Rundschau. Organ des Vereines der Architekten und Ingenieure

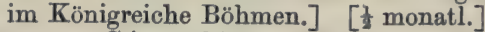

Travaux Géographiques Tchèques. (Institut Géographique de l'Université Tchèque.) Prague. [irrégul.]

Verbandlungen der Deutschen Sektion der Ärztekammer für das Königreich Böhmen. Prag. 
Prag, Vẻstn. Ċesk. Profess. Vèstník Českých Professorů. Vydává Ústřední Spolek Českf́ch Professorů v. Praze. Praha. [Anzeiger der Tschechischen Professoren. Herausgegeben vom Zentralverein der Tscheohischen Professoren in Prag, 2 monatl.]

Prag, Věstn. České Ak. Věstník České Akademie Cloă̛ Františka Josefa Frant. Jos. pro Vøðdy, Slovesnost a Umění. Praha. Anzeiger der Tschechischen Kaiser Franz Josefs-Akademie für Wissenschaft, Literatur und Kunst.] [9 H. juhrrl.]

Prag, Tẻstn. České Spol. Věstník Královské České Společnosti Náuk. Náuk

Prag, Vẻstn. Yezdu Česk. Prírod. Lékar̆.

Prag, Vír. Zpráva České Spol. Náuk

Prag, Zemský Ryb. Vestn. Tř́ida Mathematicko-Př́rodovědecká. Praha. [Nebentitel von 305.]

Verstník Yezdu Českých Přírodozpylců a Lékar̆ů v Praze. Praha. [Anzeiger des Tschechischen Naturforscher- und ÄrzteTages in Prag. Prag.]

Výroční Zprára Královské České Společnosti Náuk. Praha. [T'schechische Ausgabe von 294.] [jährl.]

Zemskỷ Rybařský Vęstník. Organ Proního Českého Zemského Spolku Rybářského v Praze. Red. Josef Rubeníček. Praha. [Landesanzeiger für die Fischerei. Organ des Ersten Tschechischen Landesvereines für Fischerei in Prag. Prag, monatl.] [N

Prag, Zprávo Činn. Č̀esk. Odb. Zemèd.

Prag, Zpráva Technol. Prim. Mus.

Zpráva o Činnosti Českého Odboru Rady Zemědělské pro Království České. Praha. [Bericht über die Tätigkeit der tschechischen Sektion des Landeskulturrates für's Königreich Böhmen. Prag.]

[DMN

Zpráva Teehnologického Průmyslového Musea, Obchodní a Zivnostenské Komory v Praze. Praba. [Bericht des Technologischen GewerbeMuseums, der Handels- und Gewerbekammer in Prag, jährl.]

Prag, Zpráoy Spolku Arch. Zprávy Spolku Architektův a Inženýrů v Království Ceském. Red. Antonín Balsánek .... Praha. [Berichte des Vereines der Architekten und Ingenieure im Königreiche Böhmen. Gesamttitel von 308 und 286, wöchentl.]

Prag, Zpráry Spolks Geol. Zprávy Spolku Geologického v Praze. Praha [Berichte des Geologischen Vereines in Prag. Prag, t jährl.]

Prakt. Ldioirt, Wien .. Der Praktische Landwirt. Illustriertes landwirtschaftliches Wochenblatt, zugleich Unterhaltungsblatt für den Landwirt. Wien. [wöchentl.]

312

Pravik, Ungariseh - Hra. disch

Pravěk. Ústreední List pro Praehistorii a Anthropologii zemí Českých. Vydavatel J. I. Červinka v Uherském Hradišti. [Urzeit. Zentralblatt für Prähistorik und Anthropologie der Tschechischen Länder. Herausgeber J. L. ¿ervinka. Ungarisch - Hradisch, 2 monatl.] 
Pražské Hospod. Nov., Pražské Hospodářské Noviny. Obrázkový Prag Časopis Věnovaný Veškerým Odvětvím a Potřebám Hospodářským. Red. Jakob Loukota. Praha. (Prager Landwirtschaftliche Zeitung. Illustrierte 'Zeitschrift für alle Zweige und Bedürfnisse der Landwirtschaft. Prag, 2 monatl.]

$[\mathrm{DMN}$

\section{R}

Reichenberg, Bienenvater..

Der Bienenvater aus Böhmen. Monatsschrift des ..... Landesvereines zur Hebung der Bienenzucht Böhmens. Reichenberg. [monatl.]

Reichenberg, Jahrb. Dtsch. GebVer. JeschkenRiesengeb.

Reichenberg, Mitt. Nordböhm. GewMus.

Jahrbuch des Deutschen Grebirgsvereines für das Jeschken- und Isergebirge. Reichenberg. [jährl.]

Mitteilungen des Nordböhmischen Gewerbemuseums. Fachredakteur Gustar E. Pazaurek.

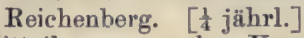

Reichenberg, Mitt. Ver. Mitteilungen aus dem Vereine der Naturfreunde NatFrde. in Reichenberg. Red. т. Karl Hübner. Reichenherg. [jährl.]

Res. Grundwasser Nieder- Resultate der Beobachtungen über die Grundschl. Wien, Wien und Donauwasserstände, dann über die Niederschlagsmengen in Wien. Erhoben und zusammengestellt rom Bauamte der Stadt Wien. Wien. [jährl.]

Riv. Dalmat., Zara _. Rivista Dalmatica. Zara. [ogni 2 mesi.]

Riv. Per. Naut., Triest .. La Rivista. Periodico Nautico. Organo dei Capitani, Ufficiali e Macchinisti della Marixa Mercantile Austro-Ungarica. Trieste. [mensile.]

Riv. Trid., Trento.. . . La Kivista Tridentina. Periodico Scientifico Let terario. Edito per Cura dell' Associazione Universitaria Cattolica Trentina. Trento. [trimestr.]

Rolnický Obzor, Iglau .. Rolnický Obzor. Noviny věnované Rolnicton a jetso Potřebám. Ihlava [Ackerbau-Rundschau. Blätter für Ackerbau und seine Bedürfnisse. Iglau. [monatl.] [DMN

Rovereto, Atti Acc. Sci. .. Atti della I. R. Accademia di Scienze, Lettere ed Arti degli Agiati in Rovereto. Rovereto. [trimestr.]

Rozhledy, Prag .. $\quad$.. Rozhledy. Týdenník pro Politiku, V̌̃du, Literaturu a Umění. Praha. [Rundschau. Wochenschrift für Politik, Wissenschaft, Literatur und Kunst. Prag.] [wöchentl.]

Rudnitz, JahrBer. Moor- Jahresbericht über die Tätigkeit der MoorkulturkultVersstat. versuchsstation in Rudnitz. Wien. [jäbrl.]

\section{S}

Saaz, Mitt. HopfenProd.

Mitteilungen des Verbandes der Saazer Hopfenproductions - Gremeinden. Red. v. Norbert Cziharz. Saaz. [monatl.]

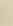

Saazer Hopfen- und Brauerzeitung. Erste allgemeine Brauer- und Hopfenrevue. Red. v. Anton Dittrich. Saaz und Wien. [46 H jährl ] 
Saccharum, Wien.. . . Saccharum. Zentralblatt für die ÖsterreichischUngarische Schokolade- und Zuckerwarenindustrie. Wien. [monatl.]

$[\mathrm{BD}$

Salzb. LandioBl., Salzburg

Salzburger Landwirtschaftsblätter. Salzburg. [t monatl.]

[DMN

Salzburg, Mitt. Ges. Salzb. Mitteilungen der Gesellschaft für Salzburger LdKde.

Landeskunde. Salzburg. [järhl.] [P

Sarajevo, Glasn. ZemMuz. Glasrik Zemaljskog Muzeja u Bosni i HerceBosn. Herceg. govini. Urednik K. Hörmann. Sarajevo Enzeiger des Landesmuseums für Bosnien und die Hercegovina.] [ $\frac{1}{4}$ jährl.]

Sarajevo, Wiss. Mitt. Bosn. Wissensehaftliche Mitteilungen aus Bosnien und Herceg.

der Hercegovina. Herausgegeben vom Bosnisch - Hercegovinischen Landes-Museum. Red. v. Moritz Hoernes. Wien. [jährl.]

Sbirk. Priedn. Lékařsk., Sbírka Yrednášek z Oboru Lékařského. Praha. Prag

Sborn. Klin., Prag [Sammlung von Vorträgen aus dem Gebiete der Medizin. Prag, 6 wöchentl.] [OQR .. Sborník Klinický. Časopis pro Pěstování Vědy Léksřské ...... Red. J. Thomayer, E. Maixner, K. Maydl. Praha. [Klinisches Magazin. Zeitschrift für ärztliche Wissen-

Sborn. Poliklin., Prag .. $\begin{gathered}\text { schaft] }[10 \mathrm{H} \text {. jährl.] } \\ \text { Sborník Poliklinický. Práce z České Univer- }\end{gathered}$ sitní Poliklinicky. Praha. [Poliklinisches Magazin. Prag. $]$ [OQR

Schles. Imker, Troppau .. Der Schlesische Iinker. Troppau. [2 monatl.]

Schönm. SchuhLdrInd., Schönmanns Schuh- und Lederindustrie ${ }^{[\mathrm{N}}$ Wien $\quad$ ausg. v. S. Schönmann. Wien. [wöchentl.]

[BD

Schralbe, Wien .. . . Die Schwalbe. Berichte des Komitees für ornithologische Beobachtungs-Stationen in Österreich. Herausgegeben von der Ornithologischen Sektion der k. k. ZoologischBotanischen Gesellschaft in Wien. Red. v. Ludwig Ritter Lorenz ion Liburnau. Wien. [2 jährl.]

[N

Schweickh.Zs. Gas-Wass., Schweickharts Zeitschrift für das Gas- und Wien

Wasserfach. Organ für die gesante Beleuchtungsindustrie, Wasserversorgung und sanitarische Branchen. Herausgeg. v. Christ[ian] F. Schweickhart. Wien u. Leipzig. [ monatl.]

Sebastivasberg, JahrBer. Jahresbericht der Moorkulturstation in SebasMoorkult Stat.

SeifensiedZtg. Wien .. tiansberg. Wien. [jährl.] [DM

Wiener Seifensieder-Zeitung. Fachorgan der österreichisch-ungarischen Seifen-, Kerzea., Parfumerie-, öl- und Fettwarenindustrie und des einschlägigen Handels. Wien. [wöchentl.]

skolski Vjesnik, Sarajeon

Slánsky Obzor, Schlan .. Slánský Obzor. [Schlsner Kevue. Jahrbuch des Musealvereines in Schlan. Schlan, f jührl.]

SpezRev. Vervioh Wes, Spezialrevue für Versicherungswesen, Finanz-, Wien Volkswirtschaft und Verkehr. Wien. monatl.] 


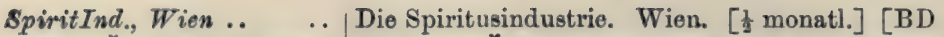
Spolk. Čas. Lesn. Mystiv. Spolkový Časopis pro Lesnictví, Myslivost a Přrod., Prag Přírodovědu. Věstník Zemské Lestnické Výzkumné Stanice pro Království České. Red. Bedř. Croy, V. Sallaě. Praha. [2 monatl.] [Net entitel von 390.]

Stat. Nachr. Landw., Wien

Statistische Nachrichten aus dem Gesamtgebiete der Landwirtschaft. Wien. [ [ monatl.]

Sïdmähr. Landw. $B l$., Südmährische Landwirtschaftliche Blätter. Znaim Monatsschrift für landwirtschaftliche Interessen. Red. v. Friedenfeldt. Znaim. [monatl.]

$[\mathrm{DMN}$

\section{T}

Techn. Jahrb. BuchKunst- Technisches Jahrbuch für den Buch- und druck, Hallein Kunstdruck, sowie alle verwandten $\mathbf{Z}$ weige. Hallein. [6 wöchentl.]

TechnNaturw. Zeit, Wien

Techniker Wien

Die Technisch - Naturwissenschaftliche Zeit. Wien. [zwanglos.]

Teplitz, TätBer. MusGes.

Tetsch. Ztg Gewb. Landw., Tetschen

Textilni Listy, Prag

Der Techniker. Wien. [ $\frac{1}{2}$ monatl.

Tätigkeitsbericht der Museums - Gesellschaft Teplitz. Teplitz. [jäbrl.]

Tetschener Zeitung tür Gewerbe und Landwirtschaft. Tetschen. [monatl.]

Textilirí Listy. Časopis pro Povzneseni Českého Textilního Průmyslu. Praha. [Textil-Blätter. Zeitschrift zur Hebung der tschechischen Textilındustrie. Prag, monatl.]

$[\mathrm{BD}$

Tir. Landw. Bl., S. Michele Tiroler Landwirtsehaftliche Blätter. Amtliches Organ der I. Sektion des Tiroler Landes. kulturrates. Herausgegeben von der Landwirtschaftlichen Landeslehranstalt und Versuchsstation in S. Michele unter Mitwirkung der Landwirtschaftlichen Landesanstalt in

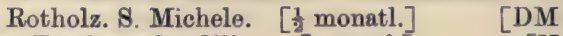
Tierfreund, Wien.. .. Der Tierfreund. Wien. [monatl.] [N

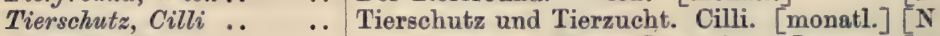

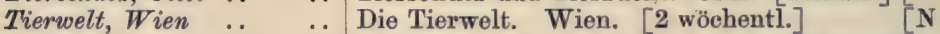
Tridentum, Trento _. Tridentum. Rivista Mensile di Studí Scientifici. Trento.

Trient, Ann. Soc. Alpin. Società degli Alpinisti Tridentini. Annuario. Trid.

Trient, Boll. Agric. $\quad$.. Trento.

Bollettino della Sezione di Trento del Consiglio Provinciale d'Agricoltura pel Tirolo, dei Consorzi Agrari distrett. e dell' Istituto Agrario Provinciale di S. Michele. Trento. [mensile]

Truent, Boll. Ass. Vinic. Vitic.

Triest,AstronNaut. Ephem.

Bollettino della Associazione Vinicola e Viticola del Trentino. Trento. [52 N. all'anno $][\mathrm{M}$ Astronomische Nautische Ephemeriden. Deutsche Ausgabe. Über Veranlassung der Marinesektion des k. u. k. Reichskriegsministeriums herausgegeben vom AstronomischMeteorologischen Observatorium der k. k. Handels- und Nrutischen Akademie in Triest. Triest.

Trieste, Amico dei Campi

L'Amico dei Campi. Periodico Mensile di Agricoltura ed Orticoltura della Società Agroria in Trieste. Red. dal Francesco Zaratin. Trieste.

[DMN 
Trieste, Atti Soc. Ing. Arch.|Atti della Società degli Ingegneri o degli Architetti di Trieste. Trieste. [irregol.]

Trieste, Boll. Soc. Adriat. Bollettino della Societd Adriatica di Scienze Sci. Nat. Naturali in Trieste. Red. Antonio Valle. Trieste. [irregol.]

Trieste, Boll. Soc. Zoofila

Bollettino Mensile della Società Zoofila. Trieste.

Trieste, Rapp. Ann. Osserv.

Rapporto Annuale dell' Osservatorio Marittimo Maritt. di Trieste, contenente le osservazioni meteoro. logiche, mareografiche e fenologiche di T'rieste e le osservazioni meteorologiche di alcune altre stazioni adriatiche. Trieste.

Trieste, Tourista .. . . Il Tourista. Bollettino Trimestrale del Club Touristi Triestini. Trieste.

Troja, JahrBer. Pomol. Jahresbericht des k. Böhmischen Pomologischen LdInst.

Troppau, JahrBer. Mus... Landesinstitutes in Troja. Prag. [jährl.] [M Kaiser Franz Josef-Museum für Kunst und Gewerbe in Troppau. Jahresbericht. Troppau. [jährl.]

Troppan, Mitt. Mus. .. Mitteilungen des Kaiser Franz Josef-Museums für Kunst und Gewerbe in Troppau. Troppau. [ $\frac{1}{4}$ jährl.]

Troppas, Mitt. Natw. Ver. Mitteilungen des Naturwissenschaftlichen Vereines in Troppau. Troppau.

\section{U}

Union, Wien $\quad$.. .. Union. Zeitschrift für Verzicherungswesen. Wien. [wöchentl.]

\section{$\nabla$}

Véda a Práce, Prag _. Vèda a Práce. Vynálezy a Pokroky na Poli Průmyslu, Obchodu a Rermesel. Red. Vilém Kurz. Praha. [Wissenschaft und Arbeit. Erfindungen und Fortschritte auf dem Gebiete der Inclustrie, des Handels und der Handwerke. Prag, t monatl.]

Verk. Öst. .Forstkongr., Verhandlungen des Österreichischen ForstWien kongresses. Wien. [zwanglos.]

TerkehrsZtg, Wien .. Verkehrszeitung. Wien. [wöchentl.]

VerordBl. Aichwesen, Wien

Verordnungsblatt für das Aichwesen im Verwaltungsgebiete des k. k. Handelsministeriums. Wien. [zwanglos.]

VerordBl. Eisenb. Schiff., Verordnungsblatt für Eisenbahnen und SchifWien

fahrt. Redigiert rom k. k. Eisenbahnministerium im Einvernehmen mit dem k. k. Handelsministerium. Wien. [t wöchentl.] [B

Ter\$chr. ForstJagdNat- Vereinsschrift für Forst-, Jagd- und Naturkde, Prag kunde. Organ der Forstlichen Landesversuchsstelle für das Königreich Böhmen. Red. v. Fried[rich] Oroy und W. Sallač. Prag. [2 monatl.]

[DM

Der Versicherungsfreund und Volkswirtschaftliche Post. Internationales Organ für Assekuranz und Volkswirtschaft. Red. v. Hermann Loewenthal. Wien, Berlin. [36 H. jährl.] 
Vesmir, Prag ．. $\quad$.. $\mid$ Vesmír. Praha. [Das Weltall. Zeitschrift für die Verbreitung naturhistorischer, geo- und ethnographischer Kenntnisse. Prag, $\frac{1}{2}$ monatl.]

Věstn. Slov. Starožitn., Věstník Slovanských Starožitností,-Indicateur des travaux relatifs à l'Antiquité Slave.Vydává Lubor Niederle. Praha. [jährl.] [P

TierteljHfte Geogr. Un- Vierteljahrshefte für den Geographischen Unterr., Wien terricht. Herausgegeben von Franz Hei-

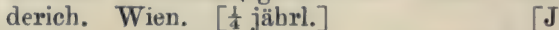

Vinarski Vrtn. List, Triest Vinarski in Vrtnarski List. Vinogradnikom Sadjarjem in Vrtnarjem $\mathrm{v}$ Pouk. Ureduje Anton Štrekelj. Trst. [W ein- und Gartenbaublatt. Den Weinbauern, Obstbauern und Gärtnern zur Belebrung. Triest. monatl.]

VolksbildBl., Krems _. Volks-Bildungs-Blätter. Herausgegeben rom Allgemeinen Niederösterreichischen Volksbildungsvereine. Red. v. Josef Wichner. Krems. [monatl.]

Volksw. WochSchr., Wien Volkswirtschaftliche Wochenschrift von Alexander Dorn. Organ für die Mitteilungen des Österreichisch-Ungarischen Exportvereines. Wien. [wöchentl.]

\section{W}

Waidmannsheil,Klagenfurt Waidmannsheil. Illustrierte Zeitschrift für Jagd, Fischerei, Schützen- und Hundewesen. Red. v. Friedrich Leon. Klagenfurt. [t/ monatl.]

Waidwerk, Saar ... .. Das Waidwerk Sar in Mähren [5 wöchent] Waidwerk, Wien... .. Waidwerk und Hundesport. Red, v, Kar]

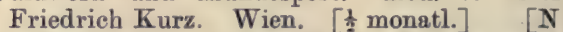

Weinlaube, Klosterneuburg Die Weinlaube. Zeitschrift für Weinbau und Kollerwirtschaft. Herausgeg. u. red von A[ugust] Freikerrn von Babo. Klosterneuburg. [wöchentl.] [M

Wettendf. SpiritInd., Wien Wettendorfers Zeitschrift Die Spiritusindustrie. Unabhängiges Fachblatt für die Spric-, Liqueur-, Branntwein-, Essig-, äther. Öleund Essenzenbranche und alle verwandten Fächer. Red. v. G. Wettendorfer. Wien. [ $\frac{1}{2}$ monat].]

[BD

Wien, Abh. Geogr. Ges... Abhandlungen der k. k. Geographischen Gesellschaft in Wien Red. v. August Böhm Edlen von Böhmersheim. Wien. [zwangl s.]

Wien, 4 4h. Geol. RchsA nst. Abhandlungen der k. k. Geologischen ReichsAnstalt. Wien. [za anglos.]

Wien, Abh. ZoolBot. Ges.

Abhandlungen der k. k. Zoologisch-Botanischen Geselischaft in Wien. Red. v. Anton Handlirsch. Wien. [zwanglos.] [LMN

Wien, Allg. AutomZtg .. Allgemeine Automobil - Zeitung. Offizielles Organ des Österreichischen Automobilklubs und des Deutschen Automobilklubs. Wien. [wöchentl.]

Wien, Alm. Ak.Wiss. .. Almanach der Kaiserlichen Akademio der Wissenschaften. Wien. [jährl.] 
Wien. Ann. NatHist. Hof- Annulen des k. k. Naturhistorischen Hofmus. museums. Redig. von Franz Steindachner. Wien. [t jährl.]

Wien, $A n z . A k$. Wiss. .. Anzeiger der Kaiserlichen Akademie der Wissenschaften Mathematioch - Naturwissen. schaftliche Klasse: [27 H. jährl.]

Wien, Arb. Neurol. Inst. Arbeiten aus dem Neurologischen Institute Wr Univ. [Institute für Anatomie und Physiologie des Zentralnervensystems] an der Wiener Universität. Herausgegeben von Heinrich Obersteiner. Wien und Leipzig. [zwanglos.]

Wien, Arb. Zool. Inst. Arbeiten aus den Zoologischen Instituten der Univ. Univer-ität Wien und der Zoologischen Station in Triest. Herausgeg. v. Karl Grubben und Berthold Hatschek. Wien. [zwanglos.]

Wien, AstrGeod. Arb. MilGeogr. Inst. sung. Die Astronomisch-Geodätischen Arbeiten des k. u. k. Militär-Geographischen Institutes in Wien. Herausgegeben rom $\mathrm{k}$. u. k. Militär - Feographischen Institute. Wien. [zwanglos.]

Wien, Astron. Kal. .. Astronomischer Kalendar. Herausgegeben von der k. k. Sternwarte zu Wien. Wien. [jährl.]

Wien, Beitr. Hydrogr. Öst.

Beiträge zur $\mathrm{H}$ ydrographie Österreichs. Herausgegeben vom k. k. Hydrugraphischen Zenira]-Bureau. Wien. [zwanglos.] [J

Wien, Beitr. Pol. Geol. Beiträge zur Paläontolngie und Geologie ÖstUng. Österreich-Ungarns und des Orients. Mitteilungen des Paläotonlogischen und Geologische" Instirutes der Universität Wien. Herausgegeben mit Unterstützung des hohen Ministeriums für Kultus und Unterricht von Viktor Uhlig und G[ustav] von Arthaber. Wien. [t jährl.]

$[\mathrm{KH}$

Wien, Ber. Altert Ver.

Wien, Ber. Ter. Geogr. Univ.

Wien, Bienenvater

Berichte und Mitteilungen des Altertums. vereines zu Wien. Wien.

Bericht über das .... Vereinsjahr, erstattet vom Vereine der Geographen an der Universität Wien. Wien. [zumeist alljährl.] [J

Bienenvater. Organ des Bienenzüchtervereines in Wien und dessen $\mathrm{Z}$ weigvereine. Red. v. Alois Alfonsus. Wien. [monatl.] [N

Wien, Bl. Ver. Ldkde Blätter des Vereines für Landeskunde von Niederösterreich. Red. v. Anton Mayer. Wien. [monatl.]

Wien, Denkschr. Ak. Wiss. Uenkschriften der Kaiserlichen Akademie der Wissenschaften, Mathemat isch-Naturwissenschaftliche Klasse. Wien. [zumindest jährl.]

Wien, Gebirgsfreund .. Jer Gebirgsfreund. Zeitschrift des Niederösterreichischen Gebirgsvereines. Red. v. Hugo Gerbers. Wien... [monatl.] [P

Wien, Graph. Revue .. Graphische Revue Österreich - Ungarns. Herausgegeben von der Wiener Graphischen Gesellschaft. Wien. [monatl.] [BD Wien, HdlMus. . . . . Das Handelsmuseum. Mit Beilagen : Monats-, Quartals- und Jahresberiohte der k. u. k. ()sterreichisch. Ungarischen Konsularïmter. Herausgegeben vom k. k. Österreichischen Handelsmuseum. Wien. [wöchent]. 
Wien, Jahrb. AckerbMin.

Wien, Jahrb. Geol. Rehs. Anst.

Wien, Jahrb. Hydr. Zen'rBur.

Wien, Jahrb. LandwGes.

Wien, Jahrb. Psychiatr. Neurol.

Wien, Jahrb. ZentrAnst. Met. Erdmagn.

Wien, JahrBer. Entom. Ver.

Wien, JahrBer. Ges. Förd. NatHist. Erf. Orient.

Wien, JahrBer. Ver. Öst. VersStat. Brauerei

Wien, JahrBer. SonnblickVer.

Wien, JahrBer. ZentrTer. BienZuchtÖst.

Wien, Mitt. Anthr. Ges...

Wien, Mitt. ErdbebKomm. Ak. Wiss.

Wien, Mitt. Geogr. Ges...

Wien, Mitt. Ges. Inn. Med. Mitteilungen der Gesellschaft für Innere Me-

Wien, Mitt. GewHyg. Mus. Mitteilungen des Gewerbe-Hygienischen Mu-

Wien, Mitt. Industr Klub... .

Wien, Mitt. KlubStaatsdruck.

Wien,Mitt. MilGeogr. Inst.

Wien, Mitt. NiedÖst. Forstver. dizin in Wien. Herausgegeben von [Hermann] Nothnagel. Red. v. H[ermann] Schlesinger. Wien. [2 wöchentl., ınit Ausnahme der Universitätsferien.] [OQR seums in Wien. Wien. [10-12 H. jährl.]

Statistisches Jabrbuch des k. k. Ackerbauministeriums. Wien. [2-3 H. jährl.]

Jahrbuch der k. k. Geologischen Reichs-

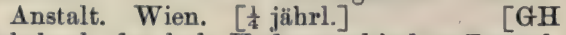
Jahrbuch des k. k. Hydrographischen ZentralBureaus. Wien. [jährl.]

Jahrbuch der k. k. Landwirtschafts-Gesellschaft in Wien. Red. v. Josef Häusler. Wien. [jährl.]

[DMN

ahrbücher für Psychiatrie und Neurologie. und Neurologie in Wien. Red. v. J. Fritsch, H. Obersteiner, A. Pick und J. Wagner v. Jauregg. Wien und Leipzig [jährl.] $[\mathrm{OQ}$ Jahrbücher der k. k. Zentral-Anstalt für Meteorologie und Erdmagnetismus. Wien. [jährl.]

Jahresbericht des Wiener Entomologischen Vereines. Wien. [jäbrl.] [N Jahresbericht der Gesellschaft zur Förderung der Naturhistorischen Erforschung des Orients in Wien. Wien. [jährl.]

Jahresbericht des Vereines der Österreichischen Versuchsstationen für Brauerei und Mälzerei in Wien. Wien. [jährl.] [BD

Jahresbericht des Sonnblick-Vereines. Wien. [jährl.]

Jahresbericht des.... Zentralvereines für Bienenzucht in Österreich. Wien. [jährl.]

Mitteilungen der Anthropologischen Gesellschaft in Wien. Red. v. Leo Bouchal. Wien. [2 monatl.]

Mitteilungen der Exdbeben-Kommission der Kaiserlichen Akademie der Wissenschaften in Wien. Wien. [zwanglos.] schaft in Wien. Red. v. August Böhm Edlen von Böhmersheim. Wien. [2 monatl.]

[DQR

Mitteilungen des Industriellen-Klubs. Heraus-

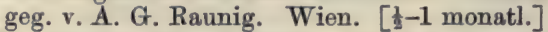

Mitteilungen und Vorträge aus den Monatsversammlungen des Fachtechnischen Klub der Beamten und Faktoren der K. K. Hofund Siaatsdruckerei. Wien.

Mitteilungen des k. u. k. Militär-Geographischen Institutes. Herausgegeben auf Befehl des k. u. k. Reichs-Kriegs-Ministeriums. Wien. [jährl.] Herausgegeben vom Vereine für Psychiatrio

Mitteilungen der k. k. Geographischen Gesell- 
Wien, Mitt. NiedÖst. Mitteilungen des Niederösterreichischen JagdschutzVer. Jagdschutzvereines. Red. v. Adolf Trenkle. Wien. [10 H. jährl.] vereines. Red. v. Heinrich v. Kadich. Wien. [10 H jährl.]

Wien, Mitt. Öst. Mus. Mitteilungen des k. k. Österreichischen Kunst Ind.

Museums für Kunst und Industrie. Wien. [monatl.]

Wien. Mitt. Ost. RchsBd. Mitt eilungen des Österreichischen Reichsbundes Vogelk. für Vogelkunde und Vogelsehutz in Wien. Wien. [monatl.]

Wien, Mitt. Pferdez. . . Mitteilungen der VI. Sektion (für Pferdezucht) der k. k. Landwirtschafts-Gesellschaft in

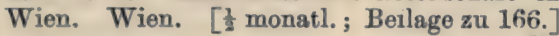

Wies, Mitt. Phot. PrivLabor. Hinterberger

Mitteilungen aus dem Photographischen PrivatLahoratorium des Universitäts-Lehrers Hugo Hinterberger. Wien. [zwanglos.] [ $\mathrm{BC}$

Wien, Mitt. Prähist. Komm. Mittellungen der Prähistorischen Kommission der Kaiserlichen Akademie der Wissenschaften. Wien. [zwanglos.] [P

Wien, Mitt. Sekt. Natkde

Milteilungen der Sektion für Naturkunde des Österreichischen Touristen-Klubs. Red. v. C. R. von Keissler. Wien. [monatl.]

Wien, Mitt. Technol. Mitteilungen des k. k. Technologischen Gev.Mus.

Gewerbe - Museums in Wien. Red. v. W[ilhelm] Exner etc. Wien. [4-5 H. jährl.]

Wien, Mitt. Ver. Verbr. Landw. Kenntn.

Mitteilungen des Vereines zur Verbreitung Landwirtschaftlicher Kenntnisse. Red. v. Wilhelm Bersch. Wien. [10 H. jährl.]

Wien, Mitt. Wr.Jagdklub Mitteilungen des Wiener Jagdklubs. Wien. [monat1.] $[\mathrm{N}$

Wien, Mitt. Wr. Med. Mitteilungen des Wiener Medizinischen Doktorenkollegiums. Red. v. Franz Batsy.
Wien. [2 wöchentl.]

Wien, Mitt. ZentrKomm. Denkm.

Wien, Mitt. ZentrVer. Fluss Kanalschiffahrt Öst.

Wien, Mon Bl.Altert. Ver.

Mitteilungen der k. k. Zentralkommission für Erforschung und Erbaltung der Kunst- und historischen Denkmale. Wien. [i. d. Regel monatl.]

455

456

Mitteilungen des Zentralvereines für Fluss- und Kanalschiffahrt in Österreich, vormals DonauVereines. Wien. [monatl.]

Monatsblatt des Altertumsvereines zu Wien. Wien. [monatl.]

Wien, MonBl. Numism. Monatsblatt der Numismatischen Gesellschaft Ges.

Wien, Mon Bl. Ver. Landeskde in Wien. Wien. [monatl.] $[\mathrm{P}$

Monatsblatt des Vereines für Landeskunde von Niederösterreich. Wien. [monatl.] [P

Wien, MonBl. Wiss. Klub. Monatsblätter des Wissenschaftlichen Klubs in Wien. Red. v. Felix Karrer. Wien. [monatl, mit zwanglosen Beilagen.]

Wien, MonHfte. Chem. .. Monatshefte für Chemie und verwanate Teile underer Wissenschaften. Gesammelte Abhandlungen aus den Sitzungsberichten der Kais. Akarlemie der Wissenschaften. Wien. [monatl.]

Wien, Naturfreund $\quad \therefore$ Der Naturfreund. Mitteilungen des TouristenVereines "Die Naturfreunde" in Wien.

Wien. [monatl.] 
Wien, Öst. AlpZtg

Wien, Öst. TourZtg

Wien, Org. Ver. Bohrtechn.

Wien, Phot. Korr.

Wien, PhotZtg. .. ..

Wien, Publ. Kuffner Sternw.

Wien, Schr. Allg. Öst. ApothVer.

Wien, Schr. Ver. Verbr. Natw. Kenntn.

Wien, SitzBer. Ak. Wiss.

Wien, SitzBer. Anthr. Ges.

Wien, Soc. Rdsch... ..

Wien, Stat. MonSchr. ..

Wien, Tierärztl. ZentrBl.

Wien, Verh. Geoly. RchsAnst.

Wien, Verh. Öst. Gradmess Komm.

Wien, Verh. ZoolBot. Ges.

Wien, VierteljBer. Phys. Chem. Unterr.

Wien, Vortr. Abh. Öst. LeoGes.
Österreichische Alpenzeit ung. Organ des Österreichischen Alpenklubs. Wien. [2wöchentl.] $[\mathrm{P}$ Österreichische Touristenzeitung. Hersusgegeben vom Österre1chischen Touristenklub.

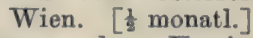

$[\mathrm{P}$ Organ des Vereines der Bohrtechniker.

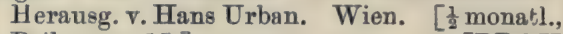
Beilage zu 15.] [BDGH

Photographische Korrespondenz. Eigentum der Photographiseken Gesellsehaft in Wien. Zeitschrift für Photographie und verwandte Fächer. Red. v. Josef Maria Eder u. Ludwig Schrank. Wien. [monatl.] [BC

Wiener Freie Photographen-Zeitung. Zeitschrift für Photographie und verwandte Fächer. Heraasgegeben rom Verein Photogruphischer Hilfsarbeiter Österreichs. Wien. [monatl.]

$[\mathrm{DC}$

Publikationen der v. Kuffnerschen Sternwarte in Wien (Ottakring). Wien. [jährl.] [E

Schriften des Allgemeinen Österreich. Apothekervereines. „Oesterr. Zeitschrift für Pharmazie." Red. v. Anton J. Sicha. Wien. [wöchentl.]

Schriften der Vereins zur Verbreitung Naturwissenschaftlicher Kenntnisse in Wien. [Nebentitel:] Populäre Vorträge aus allen Fächern der Naturwissenschaft. Herausgegeben vom Vereine zur Verbreitung Naturwissenschaftlicher Kenntnisse in Wien. Wien. [jährl., bezw, in zwanglosen Heften]

Sitzungsberichte der Kaiserlichen Akademie der Wissenschaften. Mathematisch-Naturwissenschaftliche Klasse. Wien. [in 4 Abteilungen, zwanglos.]

Sitzungsberichte der Anthropologischen Gesellschaft in Wien. Wien. [zwanglos.] [P Soziale Rundschau. Herausgegeben vom K. K. Arbeitsstatistischen Amte im Handelsministerium. Wien. monatl.]

Statistische Monatsschrift. Herausgegeben von der k. k. Statistischen Zentralkommission. Wien.

Tierärztliches Zentralblatt. Herausgegeben vom Vereine der Tierärzte in Österreich. Wien. [ $\frac{1}{3}$ monatl.]

[DNQ

Verhandlungen der k. k. Geologischen ReichsAnstalt. Wien. [18 H. jährl.]

\begin{tabular}{|l|l|l|l|l} 
Verhandlungen der Österreichischen Gradmes- & 478
\end{tabular} sungs-Kommission. Wien.

Verhandlungen der k. k. Zoologisch-Botanischen Gesellschaft in Wien. Red. v. A[nton] Handlirsch. Wien. [10 H. jährl.] [LMN Vierteljahrsberichte des Wiener Vereines zur Förderung des Physikalischen und Chemischen Unterrichtes. Zugleich Organ der Chemisch-Physikalischen Gesellschaft. Red. v. Karl Haas. Wien. [ $\frac{1}{4}$ jährl.] [CDF

Vorträge und Abhandlungen. Herausgegeben von der Österreichischen Leo-Gesellschaft. Wien. [zwanglos.] 
Wien. Woeh Sehr. Gew Ver.

Wien, Woch Schr. RübenzuckInd.

Wien, ZentrBl. ÖstUng. PapInd.

Wien, Zs. Allg. Öst. Apoth Ver.

Wien, Zs. DampflessUnters. Ges.

Wien, Zs. Elektrotechn. ..

Wien, Zs. Ing $V$ er.

Wien, Zs. Naturheilver. ..

Wien, Zs. Öst. Volkskde ..

Wien, Zs. Vermess Wes. ..

Wohlfahrt, Reichenberg ..

Wr BarindZtg, Wien ..

Wr EntomolZtg, Wien ..

Wr IU. GartZtg, Wien ..

Wr Klim. Rdsck., Wien .. $\underset{W}{W} \underset{\text { Wien }}{\text { Klin. Wochschr., }}$

Wr Klinik, Wien .. $\quad$..

Wr Mfed. Presse, Wien ..

Wr $\underset{\text { Wien }}{\text { Med. Woehsehr., }}$
Wochenschrift des Niederösterreichischen Gewerbe-Vereine». Wien. [wöchentl.]

Wocheuschrift des Zentralvereines für Rübenzuckerindustrie in der Österreichisch-Ungarischen Monarchie. Wien. [wöchentl.] [BD

Zentralblatt für die Österreichisch-Ungarische Papierindustrie . . . . . Organ des Vereines der Österr.-Ungar. Papierfabrikanten und seiner Sektionen. Wien. [36 H. jährl.] [BD

Zeitschrift des Allgemeinen Österreichischen A pothekervereins. Wien. [ $\frac{1}{3}$ monatl. $][\mathrm{DQ}$ Zeitschrift der Dampfkesseluntersuchungsund Versicherungs-Gesellschaft. Wien. [monatl.]

Zeitschrift für Elektrotechnik. Organ des Elektrotechnischen Vereines in Wien. Red. v. J. Seidener. Wien. [wöchentl.] [BC Zeitschrift des Österreichischen Ingenieur- und Architekten-Vereines. Red. v. Konst[antin] Freih[errn] v[on] Popp. Wien. [wöchentl.] Zeitschrift des Ersten Wiener Naturheilvereines. Wien. [monatl.]

Zeitschrif für Österreichische Volkskunde. Organ des Vereines für Österreichische Volkskunde in Wien. Red. v. Michasl Haberlandt. Wien und Prag. [2 monatl.] [P Zeitschrift für Vermessungswesen. Organ des Vereines der Österreichischen k. k. Vermes. sungsbeamten. Wien. [ $\frac{1}{2}$ monatl.]

Die Wohlfahrt. Zeitschrift für volkstümliche Heilweise und soziale Gesundheitspflege. Red. v. Josef Beranek. Reichenberg. [monatl.]

DQR

Wiener Bauindustrie-Zeitung. Mit der Beilage „Wiener Bautenalbum." Redigiert von Josef Röttinger. Wien. [wöchentl.]

Wiener Entomologische Zeitung. R9d. v. Alfred Herschko und Edmund Reitter. Wien. [10 H. jährl.]

$[\mathrm{N}$

Wiener Illustrierte Garten-Zeitung. Organ der k. k. Gartenbau-Gesellschaft in Wien. Red. v. Altred Burgerstein u. Fr. Abel. Wien. [monatl.] [M

Wiener Klinische Rundschau. Organ für die gesamte praktische Heilkunde sowie für die Interessen des ärztlichen Standes. Red. v. F'. Obermayer und Karl. Kunn. Wien. [wöchentl.] [OQR

Wiener Klinische Wochenschrift. Organ der k. k. Gesellschaft der Ärzte in Wien. Re.l. v. Alexander Fraenkel. Wien. [wöchentl.]

OQR

Wiener Klinik. Vorträge aus der gesamten praktischen Heilkunde. Red. v. Anton Bum. Wien und Berlin. [monatl., Beilage zu 302.]

[OQR

Wiener Me lizinischo Presse. Organ für prak. tische Ärzte. Red. v. Ant on Bum. Wien. [wöchentl.]

COQR

Wiener Medizinische Wochenschrift. Red. v. Heinrich Adler. Wien. [wöchentl.] [OQR 
Wr Nähmasch. VelocZtg, Wien

Wr Zahnäratl. MonSchr., Wien

Wr Zentr Bl. Elektrotechn. Ind., Wien

Wr Zs. Kde. MorgLd., Wien

Zdravi, Prag $\quad$.. ..

Zemèdělské Listy, Prag ..

ZentrBl. Forstwes., Wien

ZentrBl. Gewōl. UnterrWes., Wien

ZentrBl. Glasind. Keram., Wien

ZentrBl. Mähr. Ldwirte, Brünn

ZentrBl. Physiol., Wien..

ZentrBl. Therapie, Wien..

ZentrOrg. ZivTechn., Wien

Živa, Prag.. . .. ..
Wiener Nähmaschinen- und Velocipède-Zeitung. Fachzeitung zur Hebung der Nähmaschinenund Fahrradindustrie. Wien. [monatl.] [B

Wiener zahnärztliche Monatsschrift. Organ für Zahnheilkunde. Red. v, Siegfried Ornstein. Wien: [monatl.] [OQ Wiener Zentralblatt für Elektrotechnische Industrie, Bau-, Beleuchtungs- und Verkehrswesen, Technik und Gewerbe. Red. v. Ludwig Klasen. Wien. [2 wöchentl.]

Wiener Zeitschrift für die Kunde des Morgenlandes. Herausg. v. J[osef] Karabacek, D[avid] H[einrich] Müller, L[eo] Reinisch,

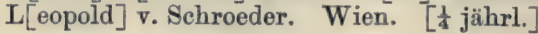

\section{Z}

Ziraví. Lidový List Veškerého Zdravotnictví a Výchovy Tělesné. Red. Duchoslav Panýrek. Praha. [Gesundheit. Volkstümliche Zeitung für praktische Gesundheits- und Körperpflege. Prag. $10 \mathrm{H}$. jährl.] \ [DQR

Zemědělské Listy. Illustrovaný Časopis věnovany Věskerým Hospodářstrí a Veřejné Spravy. Praha. [Agrikulturblätter. Illus. trierte Zeitschrift für alle Interessen der A grikultur, der landwirtschaftlichen Industrie, der Nationalökonomie und der öffentlichen Verwaltung. Prag. wöchentl.] [DMN

Zentralblatt für das gesamte Forstwesen. Organ der k. k. Forstlichen Versuchsanstalt. Herausgegeten von Josef Friedrich. Wien. [monatl.]

Zentralblatt für das Gewerbliche Unterrichtswesen in Österreich. Im Auftrage des k. k. Ministeriums für Kultus und Unterricht redigiert von Adolf Müller. Wien. [zwanglos.]

Zentralblatt für Glasindustrie und Keramik mit Generalanzeiger für die gesamte Maschinen-, Metall- und Blechindustrie. Red.v. H. Loewenthal. Wien-Berlin. [2 monatl.]

[BD

Zentralblatt für die Mährischen Landwirte. Red. v. A. Postelt. Brünn. [ $\frac{1}{2}$ monatl.]

[DMN

Zentralblatt für Physiologie. Unter Mitwirkung der Physiologischen Gesellschaft zu Berlin und der Morphologisch-Physiologischen Gesellschaft zu Wien herausgegeben von Siegmund Fuchs und J. Munk. Wien und Leipzig. [2 wöchentl.]

Zentralblatt für die gesamte Therapie. Red. v. Emil Schwarz. Wien. [monatl.] [DQR

Zentralorgan der behördlich autorisierten Ziviltechniker in Österreich. Wien. [monatl.]

Živa. Časopis Př́rodnický. Red. Bohuslav Raýman. Praha. [Živa. Ein naturwissenschaftliches Blatt]. [monatl.] 
Zivtechn., Wien .. .. Der Ziviltechniker. Zentralorgan der .... Zivilingenieure, Architekten und Geometer ... Ozterreichs. Red. v. Moriz Willfort. Wien.

Zs. Gew Hyg., Wien .. Zeitschrift für Gewerbe-Hygiene, Unfall-Verhütung und Arbeiter-Wohlfahrts-Einrichtungen. Mit dem Beiblatte : Die Fahriks-Feuer-

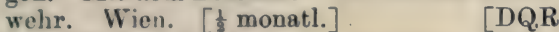

Zs. Hand. Gewb., Wien .. Zeitschrift für Handel und Gewerbe. Wien. [1 monatl.]

Zs. Heilkde, Wien $\quad$.. Zeitschrift für Heilkunde. Reil. v. H[ans] Chiari. Wien, Leipzig. [monatl.] [OQR Zs. Landw. Assek.,Wien .. Zeitschrift für Landwirtschaft, AssekuranzBank- und Verkehrswesen. Red. v. Franz Ebner. Wien.

[DMN

Zs. Landw. Gevb., Prag .. Zeitschrift für Landwirtschaftliche Gewerbe. Organ für Liqueur-, Spiritus-, Essig-, Stärkeund Hefenfabrikation, Weinproduktion und Bierbrauerei. Prag. [t monatl.] [BD Zs. Landw. VersWes., Zeitschrift für das Landwirtschaftliche VerWien suchswesen in Österreich. Vom k. k. Ackerbauministerium subventioniertes Organ für wissenschaftliche Forschung auf dem Gebiete der Landwirtschaft und der landwirtschaftlichen Gewerbe. Red. v. E. Meissl etc. Wien, Pest, Leipzig. [monatl.] [DM Zs. ObstbVer., Prag .. Zeitschrift des Obstbau-Vereines. Prag. $\left[\frac{1}{4}\right.$ jährl.]

Zs. Ost. Bautechn., Wien Zeitschrift der Österreichischen Bautechniker. Wien. [monatl.]

Zs. Ost. Gymn., Wien _. Zeitschrift für die Österreichischen Gymnasien. Red. v. J. Huemer, E. Hauler, H. v. Armin. Wien. [monatl.]

Zs. PostTelegr., Wien .. Zeitschrift für Post und Telegraphie. Fachorgan für das österreichische Post- und Telegraphenwesen, nebst verwandten Verkehrszweigen and Volkswirtschaft. Wien. monatl.]

$[\mathrm{BC}$

Zs. RealsehWes., Wien ..

Zs. Sch̆ulGeogr., Wien ..

Zeitschrift für das Realschulwesen. Red. v. Emanuel Czuber. Wien. [monatl.]

Zeitschrift für Schul-Geographie. Herausgegeben von Anton Becker. Wien. [monatl.] [J

Zs. Steierm. Forstver., Zeitschrift deз Steiermärkischen Forstvereines und Organ der Forstlichen Landesversuchsstelle für Steiermark. Red. v. V [incenz] Hess. Graz. [zwanglos.]

516

Zs. Volkswirtsch., Wien ..

Zeitschrift für Volkswirtschaft, Sozialpolitik und Verwallung. Wien. [2 monatl.]

Zs. Zakntechn., Wien ..

Zeitschrift für Zahntechnik. Wien. [monatl.]

Zs. ZuckInd., Prag ～..

Zeitschrift fü

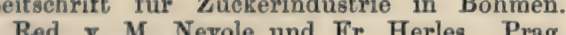
[11 H. jahrl.] [BD

Zig. LandForstevirtsch., Zeitung für Iand. und Forstwirtschaft. Organ für das geasmte Vermessungswesen, agrarische Operationen und Volkswirtschaft überhaupt. Red. v. J. Koffron. Wien. [t monatl.] [DMN Zymotechn. Rdseh., Wien.. Zymotechnische Rundschau nebst Mitteilungen aus dem chemischtechnischen Laboratorium von Dr. J. Werber und Anzeiger für die Gährungs-Industrie. Herausgeg. v. J. Werber. Wien. [4 jährl.] 


\section{ADDENDA.}

Assek. Jahrb., Wien : .. Assekuranz-Jahrbuch. Begründet von A. Ehren533 zweig,Herausg von derRedaction on der Österr. Versicherungs-Zeitung. Wien. [jährlich.]

Prag, Spisy Jub. České Spisy poctěné jubilejné cenou královskéčeskéspoSpol. Nauk lečnosti nauk $\mathrm{v}$ Praze. [Mit dem Jubilaeumspreis gekrönte Schriften der königlichen böhmischen Gesellschaft der Wissenschaften in Prag.

Prossnitz, Věstn. Kl. Při- Věstník klubu přirodovèdeckího. [Mittheilunrod.

gen des naturwissenschaftlichen Klubs. 


\section{BELGIUM.}

Rev. indust., Bruxelles .. Revue générale hebdomadaire de l'industriv nationale. Economie politique, sciences, arts. Organe de l'industrie, de la finance et des assurances, tous renseignements industriels et financiers sur la marche des affaires. Bruxelles. $\quad[\mathrm{C}$

Tongres, Bul. soc. sci. litt. Bulletin de la Société scientifique et littéraire 173 Limbourg du Limbourg. Tongres. 


\section{DENMARK.} Kjöbenhavn, Danm. Geol.
Unders. havn. 


\section{FINLAND.}

F. Mosskult. Årsb., Helsing-| Finska Mosskulturföreningens Arsbck. Helfors
singfors.

Helsingfors, C.R. Congr. Comptes-Rendus du Congrès des Naturalistes Nat. Méd. du Nord 


\section{FRANCE.}

Alençon, Bul. soc. horti. Alençon, Bulletin de la Société d'horticulture de cult.

Amiens, Mém. soc. linn. .. Mémoires de la Société linnéenne. Amiens. [F

Avignon, Bul. soc. agri- Bulletin de la Société d'agriculture et d'horticult. horticult. culture d'Avignon

Bul.météor. Hérault, Mont.

Bulletin météorologique de l'Hérault. Montpellier. pellier$$
\text { pellier. }
$$

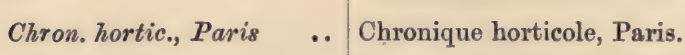

$J$. agricult. prat. économ.

Journal d'agriculture pratique et d'économie rurale, pour le midi de la France, publié par les sociétés d'agriculture de la Haute Garonne, de l'Ariège et du Tarn. Toulouse ( $\mathrm{H}^{\text {te }}$. Garonne). rurale, Toulouse

Mâcon, Bul. soc. sci. nat.

Bulletin de la Société des sciences naturelles de Mâcon (Saone et Loire).

Mans (Le), Bul. soc. horti. cult

Monde indust., Paris

Bulletin de la Société d'horticulture de la Sarthe. Le Mans (Sarthe).

- Monde industriel, Paris.

928

923

930

Paris, Bul. séan. soc. Bulletin des séances de la Société française de franç. phys. physique. Paris. 


\section{GERMANY.}

Aachen, Zs. Geschichtsver. Zeitschrift des Aachener Geschichtsrereins.| Aachen.

A6h. Gesch. Math. Wiss., Abhandlungen zur Geschichte der mathema.

1309 tischen Wissenschaften, mit Einschluss ihrer Anwendungen. Leipzig, [Zwanglos.] [A

Abh. Geseh. Med., Breslau. Abhandlungen zur Geschichte der Medicin. Hrsg. v. Hugo Magnus, Max Neuburger und Karl Sudhoff. Breslau. [Zwanglos.] [OQR

Afrika-Bote, Trier. .. Der Afrika-Bote. Nachrichten aus den Missionen der Weissen Väter in Deutsch-Ost-Afrika und in Uganda, Kongo, Nyassa, Sudan, Sahara, Kabylien. Trier.

Allg. Anz. Milcho., Hildes-

Allgemeiner Anzeiger für die gesamte Milch. wirtschaft. Hildesheim.

Allg. D. Anz. chem. Ind., Allgemeiner deutscher Anzẹiger für chemische Industrien. Berlin.

Berlin

Altbayer. Miinchen.

Altpreuss. Königsberg.

Arch. Schulpraxis, Pader. born.

Astr. geod. Arb., Mïnchen.

Altbayerische Monatsschrift. München. [C

Altpreussische Monatssshrift. Königsberg. [E

Archiv für die Schulpraxis. Hrsg. v. I. Schiffels. Paderborn. [Monatl.]

Astronomisch-geodatische Arbeiten. Veröffent. lichung der $\mathrm{kgl}$. bayerischen Commission für die internationale Erdmessung. München.

1312

1384

Aws d. Schule, Leipzig .. Aus der Schule für die Schule. Hrsg. v. A. Falke. Leipzig. [Monatl.]

Beitr. Akustik, Leipzig ..

Beiträge zur Akustik und Musikwissenschaft. Hrsg. r. Carl Strumpf. Leipzig. [Zwanglos.]

Beitr. Gesch. Niederrhein, Dusseldorf.

Beiträge zur Geschichte des Niederrheins. $[\mathrm{CQ}$ Jahrb. des Düsseldorfer Geschichts-Vereins. Düsseldorf.

Beitr. Statist. Hessen. Darmstadt.

Ber. Landw. Ostafrika. Heidelberg.

Beiträge zur Statistik des Grossherzogthums Hes. sen-Darmstadt. [mehrere Hefte jährl.]

Berichte über Land- und Forstwirtschaft in Deutsch-Ostafrika. Hrsg. v. Kais. Gouvernement Dar-es-Salam. Heidelberg. [Zwangl.]

Berlin, Jahresber. Sekt. Alpenver.

Berlin, Mitt. Prïfungeanst. Wasserversorg.

Jahresbericht der Sektion Berlin des deutschen und osterreichischen Alpenvereins. Berlin. [Jahrl.]

Mittheilungen aus der $\mathbf{K g l}$. Prüfungsanstalt für Wasserversorgung und Abwässerbeseitigung zu Berlin. Hrsg. v. A. Schmidtmann und Carl Günther. Berlin. [Zwangl.] [NQR 
Berlin, SitzBer. Math. Ges. Sitzungsberichte der Berliner Mathematischen Gesellschaft. Leipzig und Berlin

Berlin, Verh. polyt. Ges... Verhandlungen der polytechnischen Gesellschaft zu Berlin. [Zwangl.]

Bl. hess. Volksk., Giessen. Hessische Blätter für Volkskunde. Hrsg. im Auftrage der Vereinigung für Hessische Volkskunde v. Adolf Strack. Giessen. (von Münchow.) [Zwanglos.]

Braunkohle, Halle, .. Braunkohle. Zeitschrift für Gewinnung und Verwertung der Braunkohle. Halle. [CG

Bremen, Jahrb. phot. Ges. Jahrbuch der photographischen Gesellschaft zu Bremen. Bremen.

Breslau, Mitt. Sternw. .. Mitteilungen der königlichen Universitats-Stern. warte zu Breslau, hrsg. v. J. H. G. Franz. Breslau. [Zwanglos.]

CelluloidInd., Dresden .. Die Celluloid.Industrie. Beilage zur GummiZeitung. Dresden. [Monatl.] [D

Corr Bl. Fischziichter, Baut- Correspondenzblatt für Fischzüchter. Organ zen.

des Vereins deutscher Teichwirte. Bautzen [t monatl. $]$

D. Alpenztg, München

Deutsche Alpenzeitung. München.

D. Erde, Gotha .. . .. Deutsche Erde. Gotha.

D. KolBl., Berlin Schutzgebiete des Deutschen Reichs. Berlin.

D. Landw. Tierzucht, Leip. Deutsche landwirtschaftliche Tierzucht. Hr $*$ g. zig

D. met. Jahrb. Preussen ..

D. Militärärztl. Kal., Hamburg v. C. Nörner. Leipzig. [wöch.] [N Deutsches Meteorologisches Jahrbuch. Preussen und benachbarte Staaten. Hrsg ... durch U. v. Bezold. Berlin. [F

Deutscher Militärärztlicher Kalender für die Sanitätsnffiziere der Armee. Hrsg. v. A. Krocker und H. Friedheim. Hamburg. [jährl.] [DOQR

D. Müller, Leipzig _. $\quad$ Der deutsche Müller. Organ für die Interessen des deutschen Mühlengewerbes, Leipzig.

[MQ

D. Schulmann, Dessau [Berlin]

Dillingen, Jahrb. hist. Ter.

Der deutsche Schulmann. Dessau. [Jetzt Berlin]

Jahrbuch des historischen Vereins Dillingen. Dillingen a. D. (Druck v. J. Keller). [jährl.]

Eisenberg, Mitt. gesch. forsch. Ver.

Elberfield, Mitt. stat. Amt.

Mittheilungen des geschichts- und altertumsforschenden Vereins zu Eisenberg im Herzogtume Sachsen-Altenberg. Eisenberg. [zwanglos.]

$[\mathrm{P}$ Elberfeld. (Baedeker in Komm). [zwanglos.

Geisenheimer Mitt. Obstbau

Geisenheimer Mitteilungen über Obst- und Gartenbau. Hrsg. v. R. Goethe und E. Junge. Wiesbaden. [Früher , Mitteilungen über Obst- und Gartenbau."]
1369

1389

1376

1323

1324

1325

1364

1395

1326 
Geogr. Abh., Leipzig .. Geographische Abhandlungen. Hrsg. v. A. Penck. Leipzig. [zwanglos.]

1329

Geschichtsbl. Magdeburg.. Geschichtsblätter für Stadt und Land Magdeburg. [1 jahr.]

Giessen, Mitt. Gesch. Fer. Mitteilungen des oberhessischen Geschichtsvereins, Nebst Ergänzung. Fundbericht. Giessen.

Halberstadt, Jahresber. Jahresbericht der Kehr-Bolidenschen PrivatPrivat-Kliwik Kehr- Klinik in Halberstadt. Guben. [jährl.]

Boliden. [ÖQR
[Ö

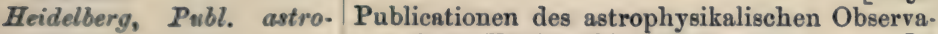
phys. Obs.

Hydrotelt, Berlin.. . .. Der Hydrotekt. Zeitschrift für Wasserversor-

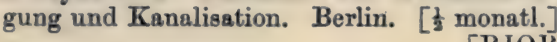

Jahrb. Eisenhüttenט., Dïsseldorf

Jahrbuch für das Eisenhüttenwesen bearb. v. O. Vogel. Düsseldorf. [jährl.]

[BDG

Jahrb. Ver. Spiritusfabr., Berlin

Jahrbuch des Vereins der Spiritusfabrikanten in Deutschland, der Stärke-Interessenten in Deutschland und der Brennerei-Berufsgenossenschaft. Berlin. [jährl.] [DMR

Jahrb. Ver. Wiss. Päd., Dresden

Jahrbuch des Vereins für wissenschaftliche Pädagogik. Hrsg. v. Th. Vogt. Dresden [jährl.]

Jahresber. soz. Hyg., Jena

Jahresbericht über die Fortschritte und Leistungen auf dem Gebiete der sozialen Hygieze und Demographie. Hrsg. v. A. Grotjahn und F. Kriegel. Jenn. [jährl.]

[QD

Jahresber. Unfallheilk., Jahresbericht der Unfallheilkunde, gerichtlichen Leipzig Medizin und öffentlichen Gesundheitspflege. Hrag. v. Placzek. Leipzig. [jährl.] [OQR

Jahressehr. Vorgesch. Sach. sen, Halle

Jahresschrift für die Vorgeschichte der sïchsisch-thüringischen Länder. Halle. [jährl.]

Kirchhoffs techn. Bl., Berlin

Kirchhoffs technieche Blätter. Wochenschrift. Berlin. [wöch.]

Lasdschaftsgärtnersi, Berlin

Landschaftsgärtnerei und Gartenarchitektur [Später : Grartentechnik]. Carlshorst. Berlin. [ $\frac{1}{2}$ monatl.]

Lehrmittel

D. Schule, Breslau

Die Lehrmittel der deutschen Schulen.

Leipzig, Jahresber. Sect. Alpenver.

Jahresbericht der Section Leipzig des Deutschen und Oesterreichischen Alponvereins. Leipzig. [jährl.]

Meer $u$. Küste, Rostock .. Meer und Küste. Internationale Zeitschrift. Hrg. v. E. Volkmann. Rostock. [18 Hefte jilhrl.]

Mineralwasser-Fabrikant, Der Mineralwasser-Fabrikant. Organ des allLübeck gemeinen Verbandes deutscher Mineralwaser-Fabrikunten. Lübeck. 
Mitt. D. Ter. Thonind., Mitteilungen des deutschen Vereins für Thon-, Berlin Cement- und Kalkindustrie. Berlin.

Mitt. milchwirtschaftlichen Ver. Allgäu, Kempten

Monatschr. Turnw., Berlin

Mïhle, Leipzig $\quad \ldots \quad$..

Mïnchen, Jahrb. hydrot. Bur.

Mittheilungen des milchwirtschaftlichen Vereins im Allgäu. Kempten. [monatl.] [QR

Monatschrift für das Turnwesen. Hrsg. v. G. Eckler. Berlin. [monatl.] [OQ

Die Mühle. Wochenschrift für die Interessen der deutschen Mühlenindustrie. Leipzig. [M

Jahrbuch des hydrotechnischen Bureaus, A btheilung der obersten Baubehörde im königlichen Staatsministerium des Innern. München.

N. Bahnen, Wiesbaden ..

N. forstl. Bl., Tübingen ...

Naturfreund, Witten $\quad$..

Oberschlesien, Kattowitz ..

Phot. Alman., Leipzig ..

Protok. intern.Komm. Luftschiffahrt, Strassburg

Quartalbl.hist.Ver.HessenDarmstadt

Quellen $u$. Forsch. alte Gesch., Leipzig

RevIngenieur, Berlin ...

Rhein. Bl. Erziehg, Frankfurt a. M.

Schles. GewBl., Breslau...

Schr. deutsch-asiat. Ges., Berlin

Sep. 4bh. Ver. Natk., Bremerhaven
Neue Bahnen. Monatschrift für Haus-, Schulund Gesellschafts - Erziehung. Zugleich Organ der Freien Vereinigung für philosophische Paedagogik. Hrsg. unter Mitwirkung namhafter Paedagogen v. H. Scherer. Wiesbaden (Emil Behrend).

Neue forstliche Blätter. Wöchentliche Rundschau hrsg. v. Anton Bühler. Tübingen. [wöch.]

Der Naturfreund, Witten.

Oberschlesien. Zeitschrift zur Pflege der Kenntnis und Vertretung der Interessen Oberschlesiens. Kattowitz.

Photographischer Almanack, hrsg. v. L. Herm. Liesegang. Leipzig. [jährl.]

[CD

Protokoll über die Versammlung der internationalen Kommission für wissenschaftliche Luftschiffahrt zu Berlin. Strassburg.

Quartalblätter des historischen Vereins für das Grossherzogtum Hessen-Darmstadt.

Quellen und Forschungen zur alten Geschichte und Geographie hrsg. v. W. Tieglin. Leipzig. [unbest.]

Revisions-Ingenieur und Gewerbe-Anwalt. Mit dem ständigen Beiblatte: Elektro-Ueberwachung. Halbmonatsschrift. Hrsg. v. W.

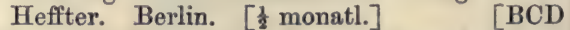

Rheinische Blätter für Erziehung und Unterricht. Hrsg. v. F. Bartels. Frankfurt a. M. [monatl.]

Schlesisches Gewerbeblatt. Organ des Breslauer und des schlesischen Central-Gewerbe-Vereins. Breslau.

Schriften der deutsch-asiatischen Gesellschaft. Hrsg. v. Vosberg-Rekow. Berlin. [zwanglos.]

[JHM

Separate Abhandlungen des Vereins für Naturkunde an der interweser. Bremerhaven. [unbestimmt.] 
Thonind., Dresden $\quad$.. $\mid$ Die Thonindustrie. Dresden. [36 Hefte jührl.]

Tübingen, Schr. Höhlewver. Schriften des Schwäbischen Höhlenvereins. 1355 Tübingen. [zwanglos.]

Terh.Tuberculosecomm. Ges. D. Natf., Berlin

Verhandlungen der standigen Tuberculosecommission der Gesellschaft deutscher Naturforscher und Aerzte. Berlin. [un. bestimmt.]

Veröff. D. Ver. Versichergswiss., Berlin

Veröff. D. Vor. Tolks-Hyg., München

Veröffentlichungen des deutschen Vereing für Versicherungswissenschaft. Berlin. [F Veröffentlichungen des deutschen Vereins für Volks-Hygiene. Hrag. v. K. Beerwald. München und Berlin.

Westd. Zs. Gesch., Irier..

Westdeutsche Zeitschrift für Geschichte und Kunst. Trier. [4 Hefte jäbrl.] Nebst Ergheft.

Zs. D. morgenländ. Ges.,

Zeitschrift der deutschen morgenländischen Gesellschaft. Leipzig.

Zs. Farbenchem., BraunZeitschrift für Farben- und Textil-Chemie. Hrsg. v. A. Buntrock. Braunschweig. [t monatl.]

Zs. gew. Unterr., Leipzig. . Zeitsclırift für gewerblichen Unterricht. Leipzig.

Zeitachrift fiir dag Gymmasin]wesen.

Zs. Gymnasiaho., Berlin ..

Zs. Versichergswiss., Berlin H. J. Müller. Berlin. [monatl.]

Zeitschrift für die gesammte Versicherungswissenschaft. Berlin.

Zs. wiss. Phot., Leipzig ..

Zwangl. Abh. med. Phot., Zeitschrift für wissenschaftliche Photographie, Photophysik und Photochemie. Leipzig.

[CEGL

Zwanglose Abhandlungen aus dem Gebiete der medizinischen Photographie, Röntgoskopie, Röntgographie und der Lichtanwendung. [Fort8. d. Intern. photogr. Monatschrift f. Medizin.] München. [zwanglos.] [CLOQR 


\section{HOLLAND.}

Amsterdam, Handl. Ned. Handelingen van de Nederlandsche Anthropo- T0 \begin{tabular}{c|c} 
Anthr. Ver. & logische Vereeniging. Amsterdam \\
Hemel en Dampkring, Hemel en Dampkring. Amsterdam. &
\end{tabular} 


\section{HUNGARY.}

Allatt. Közlem., Budapest

Budapest, Amn. Hist.-Nat. Mus. Nat. Hung.

Földt. Int. Evi Jelent., Budapest

G yermekgy. az Orv. Hetilap Mellékl., Budapest

Gynaek. az Orv. Hetilap

Gyogysz. Közl., Rudapest. .

M. Fogász. Szemle, Budapest pest

Orr-Gége-és Fulgy. az Orv. Hetilap mellékl., Budapest

Orv. Hetilap, Budapest ..

Oro. Hetilap Mellékl., Budapest

Orv. L., Budapest .

Szemész. az Oro. Hetilap Mellékl., Budapest Mellékl., Budapest

Növenyt. Közlem., Buda-

Állattani Közlemények, Budapest. [Zoologische Mittheilungen, Budapest.]

Annales Historico-Naturales Musei Nationalis Hungarici.

A Magyar Kir Földtani Intézet Évi Jelentése, Budapest. [Jahresbericht der Königl. Ungarischen Geologischen Anstalt, Budapest.]

Gyermekgyógyászat az „, Orvosi Hetilap ” Melléklete, Budapest. [Paediatrische Beilage zum Medicinisehen Wochenblatt, Budapest.]

Gynaekologia az „Orvosi Hetilap” Melléklete, Budapest.

Gyogyszerészé Közlöny, Budapest. [Pharmaceutische Mittheilungen, Budapest.]

Magyar Fogászati Szemle, Budapest. [Ungarische Zahnärztliche Revue, Budapest.]

Növénytani Közlemények, Budapest. [Botanische Mitteilungen, Budapest].

Orr-Gége-és Fülgyógyászat az „Orvosi Hetilap“ melléklete, Budapest. [Rhinologisches, laryngologisches und otologisches Beiblatt zum Medicinischen Wochenblatt, Budapest].

Orvosi Hetilap, Budapest. [Medicinisches Woch. enblatt, Budapest.

$\mathrm{Az}$ „Orrosi Hetilap “ Melléklete, Budapest. [Beilage zum Medicinischen Wochenblatt, Budapest].

Orvosok Lapja, Budapest. [Medicinisches Wochenblatt, Budapest.]

Szemészet az „Orrosi Hetilap “ Melléklete, Budapest. [Ophtalmologische Beilage zum Medicinischen Wochenblatt, Budapest.]

Ungar.Med. Rev., Budapest $\mid$ Ungarische Medicinische Revue, Budapest ..
32 


\section{INDIA.}

Rep. Bot. Surv. Ind., Cal. Annual Report of the Botanical Survey of India. 31 cutta 


\section{ITALY.}

Ann. Bot., Roma .. . . Annali di Botanica pubblicati dal prof. Romualdo Pirotta, Roma.

Anmuario Staz. patol. veg., Annuario della R. Stazione di patologia vegetale Roma.

Roma.

$[\mathrm{MR}$

Appennino Centrale, Jesi.. Archivio farmac., Roma,..

Archivio fisiol., Firenze .. Archivioital anat.embriol., Firenze.

Arehivio nevrol, Napoli.. Archivio ortoped., Milano Archivio zool., Napoli ..

L'Appennino centrale, Jesi.

Archivio di farmacologia sperimentale e scienze affini, Roma.

[MQ-R

Archivio di fisiologia, Firenze. $\quad[\mathrm{O}-\mathrm{R}$

Archivio italiano d'anatomia e d'embriologia, Firenze.

$\begin{array}{ll}\text { Archivio di nevrologia, Napoli. } & {[Q} \\ \text { Archivio d' ortopedia, Milano. } & \Gamma \mathrm{O}-\mathrm{Q}\end{array}$

[O-R

Archivio zoologico, Napoli [N-O

Boll. teen. colt. tabacchi, Portici.

Cagliari, Boll. sc."med. nat.

Camerino, Boll. Soc. Eustachiana.

Cronaca clin. med., Genova

Eoploraz, commerc., Milano

Firenze, Boll. Soc. Tosc. ostetricia.

Firenze, Bull. R. Soc. tosc. ort.

Gazz. med. ital., Pavia .. Giorn. elettr. med., Napoli

Giorn. geol. prat., Genova

Giom. ginec. pediatria. Torino.

Giorn. ital. se, med., Pisa
Bollettino tecnico della coltivazione dei tabacchi, pubblicato per cura del R. Instituto sperimentale di Scafati (Salerno)-Portici

Bollettino della Società fra i cultori dell scienze mediche e naturali, Cagliari.

[O-R

Bolletino della Societa Eustachiana, Camerino

Cronaca della clinica medica, Genova $\quad[\mathrm{O}-\mathrm{R}$

L'Esplorazione commerciale. Bollettino della Societa d'esplorazioni geografiche e commereiali, Milano.

Bollettino della Societa Toscana d'ostetricia, Firenze.

「O-R

Bulletino della R. Societd toscano d'orticultura, Firenze.

Gazzetta medica italiana, Pavia.

Giornale d'elettricità medica, Napoli.

-O-R

Giornale di geologir pratica, Genova.

Giornale di ginecologia e pediatria, Torino. [O-R 
Giorn. internaz. Med.prat., Giornale internazionale di medicina pratica, Napoli Napoli.

300

Ing. igien., Torino.. $\quad$.. L'ingegnere igienista, Torino.

Italia ortic., Napoli .. L'Italia orticola, Napoli.

Laboratorio, Torino _.. Il Laboratorio, Torino.

Malpighi, Roma ..

Manicomio, Nocera

Marcellià, Avellino

Modena, Boll. Soc. Med.chirurg.

Napoli, Annuario Museo zool.

Napoti, Boll. Soc. Afric.. .

Nuovo Raccogl. med., Forli

Redia, Portici .. ...

Riv. Clin. Pediatr., Firenze

Riv. coleottor. ital., Camerino.

Riv. internaz. Igiene Organoopoterapia, Napoli

Roma, Ann. Ist. psich. . .

Roma, Boll. Soc. zool. ital. Roma, Boll. uff. Min.Agric.

Udine "In Alto," Cron. Soc. Alp. friul.
- Malpighi, Gazzetta medica di Roma. [O-R

- Il Manicomio, Archivio di Psichiatria e scienze affini, Nocera.

Marcellià, Riviste internazionale di Ceci Avellino.

Dettino. [M Modena.

Annuario del Museo zoologico della R. Università di Napoli.

Bollettino della Societa africana d'Italia, Napoli.

Il nuovo Raccoglitore medico, Forli. [O-R

Redia, Giornale d'Entomologia, Portici.

Rivista di Clinica Pediatrica, Firenze.

Rivista coleottorologica italiana, Camerino [N

Rivista internazionale d'Igiene è di organoopoterapia, Napoli.

Annali dell' lstituto psichiatrico della $\mathrm{R}$. Università di Roma. Roma.

$[\mathrm{Q}$

Bollettino della Società zoologica italiana, Roma. Bollettino ufficiale del Ministero di Agricoltura, Industria e Commercio, Roma. [With which is incorporated No. 172.] 


\section{NEW SOUTH WALES.}

Sydney, N.S.W., Rec. Geol. | Records of the Geological Survey of New South | 


\section{NORWAY.}

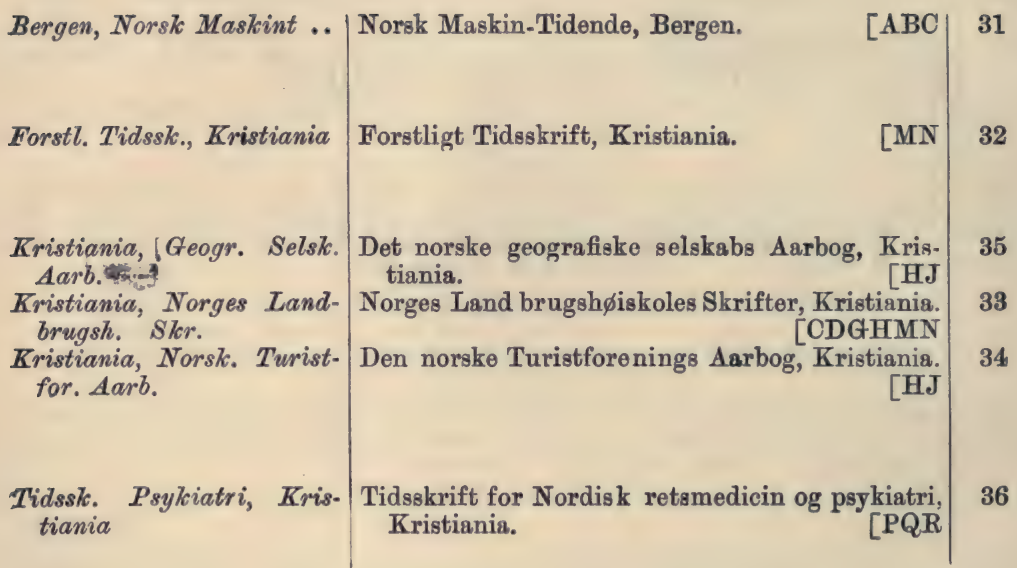




\section{RUSSIA.}

All Government Reports with their various sections will be reforred to thus :-

Name of province.

Gub. Vðdom. (Government Report).

Name of Section.

Essentuki, Otz. Ob8̌. vrač. Отчетъ Обцества врачей, практикующихъ на Кавказскихъ минеральныхъ водахъ въ Ессентукахъ, Ессентуки |[Compte-rendu de la société des médecins des eaux minérales du Caucase à Essentuki.]

$[\mathrm{OQR}$

Jaraslaviš, Mém. Soc. Nat.

Труды Ярославскаго естественно-историческаго Общества. Ярославль [Mémoires de la Société des naturalistes de Jaroslav. Jaroslav.]

453

Kavkazsk. SeTisk. |Choz.,

Кавказское сельское хозяйство. Тифлисъ Tiflis.

Kazani, Prot. Obฉ̌c. jest. .. [Economie rurale du Caucase. Tiflis.]

Протоколы засьданій Общества естествоиспытателей при Императорскомъ Казанскомь Университеть. Казань [Procèsverbaux des séances de la Société des naturalistes de l'Université Impériale de Kazan. Kazan.]

$[\mathbf{A}-\mathbf{R}$

Kiev, Izv. potitechn. Inst...

Извьстія Кіевскаго политекническаго Института Императора Александра II. Кіевъ [Bulletin de l'Institut polytechnique de l'Empereur Alexandre II. Kiev.]

Kiev, Prot. fiz.-med. Obžc. Протоколы Кіевскаго физико-медицинскаго Общества (въ Университетскихъ Извъстіяхъ). Кіевъ [Procès-verbaux de la Société physico-médicale de Kiev (dans le "Bulletín de l'Université Impériale de Kiev.") Kiev.] [COQR

Krasnojarsk, Izv. Krasn. Извђстія Красноярскаго подъ-отдыла Восotd. Russ. Geogr. Obsé. точно-Сибирскаго отдыла Имнераторскаго Русскаго Географическаго Общества. Красноярекъ [Bulletin de la sub-division Krasnoliarsk de la section de la Sibérie orientale de la Société Impériale Russe de Géographie. Krasnolarsk.] 
Krasnojarsk, Zap. Krasn.|Записки Красноярскаго подъ-отдыла ВостоOtd. Russ. Geogr. Obšč.

List. boř̌by bolèz. rastenij, St. Peterburg

Listok vinograd., vinodèl. plodov., Kišinev. чно-Сибирскаго Отдъла Императорскаго Русскаго Географическаго Общества. Красноярскъ [Mémoires de la sub-division Krasnoïarsk de la section de la Sibérie orientale de la Société Impériale Russo de Géographie. Krasnoïarsk.]

Листокь для борьбы съ бользнями и поврежденіями культурныхъ и дикорастущихъ полезныхъ растеній. С.-Петербургъ [Feuille concernant la lutte contre les maladies des plantes cultivées et spontanées utiles. St.-Pétersbourg.]

Листокъ виноградарства, винодылія и плодоводства. Кишиневъ [Journal d'oenologie, de viticulture et de culture fruitière. Kichinev.]

[DLM

More $i$ jego žiznă, St. Peterburg

Moskva, Dněv. otd. icht. Imp. R. Obšč. acclimat.

Moskva, Pam. Knižka Konst. mež. Inst.

Море и его Жизнь. С.-Петербургъ [La mer et sa vie. St.-Pétersbourg.]

Дневникь отдћла ихтіологіи Императорскаго Русскаго Общества акклиматизаціи животныхъ и растеній. Москва [Journal de la section ichthyologique de la Société Impériale Russe d'acclimatation des plantes et des animaux. Moseou.]

Памятная книжка Константиновскаго Межеваго Института. Москва [Annuaire de l'Institut d'arpentage Constantin. Moscou.]

Moskva, Trd. kruž. izsl. russ. prir.

Труды студенческаго кружка для изсльдованія русской природы, состоящцаго при Императорскомъ Московскомъ Университеть. Москва [Travaux du cercle des étudiants pour l'exploration de la nature russe, attaché à l'Université Impériale de Moscou. Moscou.]

Novočerkask, Věst. Donsk. Otděla Imp. russ. Obšč. sadovodstva

Вњстникъ Донского Отдњла Императорскаго Общества Садоводства. Новочеркаскь [Messager de la section du Don de la Société Impériale Russe d'horticulture. Novočerkask.]

$[\mathrm{DM}$

Odessa, Zap. Obšč. jest. ..

Зашиски Общества естествоиспытателей. Oдеcса [Mémoires de la Société des natura. listes d'Odessa ]

Obrazov., St. Peterburg .. [M St.-Pétersbourg.]

Poltava, Otč. Kruž. lüub. fiz.-mat. nauk

Отчетъ Полтавскаго Кружка любителей физико-математическихъ наукъ. Полтава Compte-rendu de la Société des amateurs des sciences physico-mathématiques de Poltava. Poltava.]

Практическій врачъ, С.-Петербургъ [Lе médecin practicien. St.-Pétersbourg.] 
Promyšl. i zdorov., St. Промыштенность и здоровье. С.-Петербургы Peterburg

[L'industrie et la santé. St.-Pétersbourg.]

Raboty gidrobiol. st. Glubokoe, Maskva.

Работы гидро-біологической Станціи на Глубокомъ озерь. Отдьленіе ихтіологіи Ииператорскаго Общества акклиматизаціи животныхъ и растеній. Москва [Travaux de la station hydro-biologique du lac Glubokoje. Section ichthyologique de la Société Impériale russe d'acclimatation des plantes et des animaux. Moseou.]

Recept, St. Peterburg .. Редептъ. С.-Петербургъ [L'ordonnance. St.-Pétersbourg.] [DQR

Russ. chinurg. arch., St. Русскій хирургическій архивъ. С.-Петер-
Peterburg.
бургт [Archive russe de chirurgie. St.-

431

432

Russ. chirurg. arch., St. Русскій хирургическій архивъ. С.-Петер-
Реterburg.

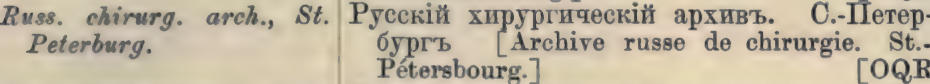

Russ. gorno-zavodsk. věst., Русскій горнозаводскій вњстникъ. С.-ПеSt. Peterburg. тербург [Gazette des usines minières russes. St..Pétersbourg.]

St. Peterburg, C. rend. Извъстія постоянной центральной сейсмиComm. sism. ческой Коммиссіи. С.-Петербургв [Сомрtes-rendus des séances de la commission sis. mique permanente. St.-Pétersbourg.]

St. Peterburg, Prot. Obšc. Протоколы засьданій Общества экспеременexpériment. psichol. (in Rev. psychiatr. névrol. psychol. exp., St. Peter. burg).

та:ььой психологіи. С. - Петербургь [Procès-verbaux de la Société de psychologie expérimentale. St. - Pétersbourg (in Rev. psychiatr. nérrol. psychol, exp., St.-Pétersbourg).]

St.Peterburg, Prot. oftalm. Протоколы Петербургскаго офталмологиObž̃. Věst. oftalm. qескаго общества (въ Выстник' офталмологіи). С.-Петербургъ [Procès-verbaux de la Société ophtalmologique de St.-Pétersbourg (dans "Messager d'ophtalmologie").]

St. Petersburg, Sborn. Inst. Сборникъ Пнститута инженеровъ Путей Put. Soobźc.

St. Peterburg, Trav. Mus. Труды ботаническаго Музея Императорской bot. Ac. Sc.

St. Peterburg, Trd. Sjězda selisk.-choz. opytn. déla

Samoobraz., St. Peterburg

Sëvern. choz., St. Peterburg Socrem. klin., St. Pelerburg

Tech, shorn. vést. promyarl., Moskva.
Сообиенія. С.-Іетербургъ [Recueil de l'Institut des ingénieurs des voies de communication. St.-Pétersbourg.] Академіи Наукъ. С.-Петербургъ [Travaux du Musée botanique de l'Académie Impériale des sciences. St.-Pétersbourg. $]$ [M

Труды съђзда дыятелей по сельско-хозяйственному опытному дылу. С.-Петербургъ [Travaux de la Conférence d'agriculture ex. périmentale à St.-Pétersbourg.]

[FL

Самообразованіе. С.-ІІетербургъ [L'autodidacte. St. - Pétersbourg.] [Ceased to appear.]

САверное хозяйство. С.-Петербургъ [Еесnomie rurale du Nord. St.-Pétersbourg.

Современная кіиника. C.-Петербургъ [La clinique contemporaine. St.-Pétersbourg.]

[OQR

441

442

451

434

436

437

лениости. Москва [Recueil technique et messager de l'induatrie. Moscou.] 
Tomsk, Arb. Med. Chem. Труды медико-химической лабораторіи ИмпеLaborat. Univ.

Trd. B. entom. Uと̌en. Kom. M. Zeml., St. Peterburg

Trd. opytn. lěsniè., St. Peterburg

Trd. pridnéprovskoj Met. sěti, Kiev.

Trd. selı̌sk.-choz. met., St. Peterburg

Varšava. Trav, soc. nat. Proc. verb. réun. gén.

Varšava, Trav. Soc. nat. Proc. verb. sect. biol.

Varšava, Trav. soc. nat. Proc. Verb. sect. phys. chim.

Vést. II. Sjëzda po klimatologii v Puatigorskè. St. Peterburg

Věst. bibl. samoobr., st. Peterburg.

Tèst. idiot, épileps, st B Peterburg.

Věst. zemled. i promyšl., Chařkov.

Zemledělec, St. Peterburg Государственныхъ Имуществъ. С.-Петер-

Выстникь Земледилія и промышленности. раторскаго Томскаго Университега. Томскь [Arbeiten des Medicinisch-Chemischen Laboratoriums der Kaiserlichen Universität zu Tomsk.]

[DQR

455

Труды Бюро по энтомологіи Ученаго Комитета Министерства Земледылія и Государственныхъ Имуществъ. С.-Петербургъ [Travaux du Bureau entomologique du Comité scientifique du Ministère d'Agriculture et des Domaines. St.-Pétersbourg.]

[N

Труды опытныхъ льсничествъ Лжсного Департамента Министерства Земледълія и бургт [Travaux des stations expérimentales forestières du Ministère de l'Agriculture et des Domaines. St.-Pétersbourg.] [FHLM

Труды приднбпровской Метеорологеческои сьти. Кіевъ [Travaux du réseau météorologique du Dniepr. Kiev.]

Труды по сельско-хозяйственной метеорологік. С.-Петербургъ [Travaux sur la météorologie agricole. St.-Pétersbourg.] · [FM

Труды Варшавскаго Общества естествоиспытателей. Протоколы общаго собранія. Варшава [Travaux de la société des naturalistes de Varsovie. Procès-verbaux de la réunion générale.]

Труды Баршавскаго Общества естествоиспытателей. Протоколы отдъленія біологік. Варшава [Travaux de la société des naturalistes de Varsovie. Comptes-rendus de la section de biologie.]

Труды Варшавскаго Общества естествоиспытателей. Протоколы отдъленія физики и химіи. Варшава [Travaux de la société des naturalistes de Varsovie. Comptes-rendus de la section de physique et de chimie.]

Вњстникъ 2го Всероссіискаго Съъвда дъятелей по климатологіи, гидрологіи п бальнеологіи въ Пятиторскь. С.-Петербургъ [Messager du 2d Congrès Russe de Climatologie, de Hydrologie et de Balnéologie à Platigorsk. St.-Peterburg.] [FOQR C.-Петербургъ [Messager et bibliothèque à l'usage des autodidactes. St.-Pétersbourg.] бургт [Messager de l'idiotisme et de l'épilepsie. St.-Peterburg.] [OQR Харьков' [Messager de l'agriculture et de l'industrie. Kharkov.]

[DM

Земледълецъ. Иллюстрированній Журналь по сельскому хозяйству и естествовнанію. С.-Петербургв [L'agronome. Journal illustré d’agriculture et de sciences naturelles. St.-Pétersbourg.] 


\section{SOUTH AFRICA.}

Bulawayo, Ann. Rep. Rhod. Mus.

Bulavayo, Proc. Rhod. Sc. Assoc.

Bulavayo, Spec. Rep. Rhod. Mus.

Cape Toron, Ann. Rep. Geol. Comm.

Cape Town, Ann. Rep. Gov. Entomol.

Cape Town, Ann. Rep. Meteor. Comm.

Cape Town, Ann. S. Afriea Mus.

Cape Town, Marin. Invest.

Cape Town, S. Afric. Med. Rec.

Cape Town, Trans. S. Afric. Phil. Soc.

Grahamstown, CapeColony, Ree. Albany Mus.

Jolannesburg, Geol. Soc. 8. Africa

Natal Plants, Durban _. Natal Plants, Durban. J. M. Wood.

Pietermaritzburg, Rep.Gov. Entomol.

Pretoria, Rep. Gov. Geol. .
Annual Rep
Bulawayo.

Proceedings of the Rhodesia Scientifio Association,

Special Report of the Rhodesian Museum, Bulawayo.

Annual Report of the Geological Commission, Cape Town.

[GHK

Annual Report of the Government Entomologiat, Cape Town.

Annual Report of the Meteorological Commission, Cape Town.

Annals of the South African Museum, Cape Town.

Marine Investigations in South Africa, Cape Town.

[JLM

South African Medical Record, Cape Town ..

Transactions of the South African Philosophical Society, Cape Town. [Includes Proceedings.] [A KL

5

6

15

7

Records of the Albany Museum, Grahamstown

12 burg.

[GHK

Report of the Government Entomologist, Pietermaritzburg.

Report of the Government Geologist. [GHK
2

3

4

14.

1

13

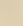

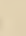
5. 


\section{SWEDEN.}

Östersund, Jämtl. Forn- Jämtlands länds Fornminnesförenings Tidskrift, $\mid 63$ minn. Tidskr. Östersund.

$[\mathrm{P}$. 


\section{SWITZERLAND.}

\section{La Sursse-Die Schweiz-Svizzera.}

(This list supersedes the previous issue.)

Aaras, Mitt. Natf. Ges... Agricolt. Ticinese, Lugano Alpina, Ziirich .. ..

Alpwirtsch. Monatsbl., Solothurn

Ann. Electro - Homöop., Genf

Anus. Club Alp. Ticinese, Bellinzona

Annu. Méd. Suisse, Berne.. Anz. Schweiz. Alterthumsk., Zürich

Arch. Sci. Phys., Gendve..

Basel, Abh. Schweiz. Pal. Ges.

Basel, Verh. Natf. Ges...

Bern, Ber. Schveiz. Bot. Ges.

Bern, Arch. Hist. Ver. ..

Bern, Jahresber. Geogr. Ges.

Bern, Mitt. Natf. Ges, ..

Boll. Med. Svizz, Lugano

Bul. Agric. Neuchatel., Cer. nier
* Mitteilungen der aargauischen naturforschenden Gesellschaft. Aarau. $8^{\circ}$.

L'Agricoltore ticinese. Lugano. $8^{\circ}$. [DMN

*Alpina. Nitteilungen des Schweizer Alpenclubs. Bulletin du Club alpin suisse. $4^{\circ}$. Zürich.

[FJ

Alpwirtschaftliche Monatsblätter. Solothurn $8^{\circ}$.

DMN

Annalen der Elektro-Homöopathie und Gesundheitspflege. Annales de l'Electro-homéopathie et d'hygiène. Genf. $8^{\circ}$.

Annuario del Club alpino ticinese. Bellinzona $8^{\circ}$.

Annuaire médical suisse. Berne. $8^{\circ}$. [OQR

Anzeiger für schweizerische Aiterthumskunde. Indicateur d'antiquités suisses. Zürich. $8^{\circ}$.

* Archives des sciences physiques et naturelles. Genève, Lausanne et Paris. $8^{\circ}$.

* Abhandlungen der schweizerischen paläontologischen Gesellschaft. Mémoires de la Société paléontologique suisse. Basel \& Genf. $4^{\circ}$.

$[\mathrm{KN}$

*Verhandlungen der naturforschenden Gesell. schaft in Basel. $8^{\circ}$. Basel.

* Berichte der schweizerischen botanischen Gesellschaft. Bulletin de la Société botanique suisse. Bern. $8^{\circ}$.

M

Archiv des historischen Vereins des Kantons Bern, Bern. 8\%.

*Jahresbericht der geographischen Gesellschaft von Bern. Bern. $8^{\circ}$.

[HJ

* Mitteilungen der naturforschenden Gesellschaft in Bern. Bern. $8^{\circ}$.

- Bollettino medico della Svizzera italiana. Lugano. $8^{\circ}$.

[OQR

Bulletin agricole neuchatelois. Cernier. $8^{\circ}$.

DMN
1

3

4

- Zeitschriften, die mit ihrem ganzen Inhalt in den Bereich des Katalog s fallen. 
Bul. Dép. Féd. Agricult., Bulletin du Département fédéral de l'AgriculBerne. (Comun. Dip. ture. Avec l'Annuaire agricole comme annexe Fed. Agricolt., Berna. Mitt. Schweiz. Landw.Dep., Bern) gratuite. Comunicazioni del Dipartimento federale dell' Agricoltura. Coll' Annuario agricolo come supplemento gratuito. Mitteilungen des schweizer. Landwirtschaftsdepartements, mit dem landwirtschaftlichen Jahrbuch als Gratisbeilage. Bern. 8०. [MN Bul. Murith., Aigle _. * Bulletin de la Murithienne, Société valaisanne des sciences naturelles. Aigle, Bex, etc. $8^{\circ}$.

[HMN

Bul. Phot., Neuchátel .. Bulletin Photographique. Neuchâtel. 5०. [CD Bündner. Monatsbl., Davos

Bündnerisches Monatsblatt. Davos. $8^{\circ}$.

Centralbl. Jagd - Liebh., Centralblatt für Jagd- und Hundeliebhaber. Zürich Zürich. $4^{\circ}$.

Chron. Agric., Lausanne.. Chronique Agricole du csnton de Vaud. Lausanne. $8^{\circ}$.

Chur, Jahresber. Natf. Ges. Graub.

*Jahresbericht der naturforschenden Gesellschaft Graubündens. Chur. $\mathbf{8}^{\circ}$.

Comun. Dip. Fed. Agricolt., Berna v. Bul. Dép. Féd. Agricult., Berne

Corr. Agric., Lugano ...

Corr. - Bl. Schweizerärzte, Basel

Corriere agricolo. Lugano. $4^{\circ}$.

DMN

*Correspondenzblatt für Schweizerärzte. Basel. $8^{\circ}$.

Diana, Genève $\quad \ldots \quad$.. Berne \& Genève. $4^{\circ}$

Echo Alpes, Genève $\quad$..

Echo Photo. Suisse, Fribourg.

Eclogæ Geol. Helvet., Lausanne P.
Feuilles Hyg., Neuchâtel..

Frauenfeld, Mitt. Thurg. Natf. Ges.

Freiheit, Base

Fribourg, Bul. Soc. Hortic.

Fribourg, Bul. Soc. Sci. Nat.
L'Echo des Alpes. Publication des sections romandes du Club Alpin suisse. Genève. $8^{\circ}$.

[HJ

Echo photographique de la Suisse. Fribourg. $8^{\circ}$. [CD

*Eclogæ geologicæ Helvetiæ. Recueil périodique de la Société géologique suisse. Mit. teilungen der schweizerischen geologischen Gesellschaft. Lausanne. $8^{\circ}$.

[GHK

Feuilles d'hygiène et de médecine populaire. Neuchâtel. $4^{\circ}$.

31

*Mitteilungen der thurgavischen naturforschenden Gesellschaft. Frauenfeld. $\mathbf{8}^{\circ}$.

Die Freiheit. Blätter zur Bekämpfung des Alkoholismus. Basel. $4^{\circ}$.

Bulletin de la Société fribourgeoise d'horticulture. Fribourg. $8^{\circ}$.

[M

* Bulletin de la Société fribourgeoise des sciences naturelles. Fribourg. $8^{\circ}$.

* Zeitschriften, die mit ihrem ganzen Inhalt in den Bereich des Katalogs fallen. 
Genève, Anwu.Conserv. Bot. *Annuaire du Conservatoire et du Jardin botaniques de Genève. Genève. $8^{\circ}$. [M

Genève, Bul. Assoc. Pro.

* Bulletin de l'Association pour la protection des Plantes. Genève. $8^{\circ}$. [M tect. Plantes .. ..

Genève, Bul. Boissier. ..

*Bulletin de l'herbier Boissier. Genève \& Bâle. $8^{\circ}$.

$[\mathrm{M}$

Genève, Bul.Inst. Nat. .. Bulletin de l'Institut national genevois. Genève. $8^{\circ}$.

Gendve, Bul. Soc. Arts Cl. Bulletin de la Société des Arts de Genève. Agric.

Genève, Bul. Soc. Arts $\mathrm{Cl}$. Classe d'agriculture. Genève. 8०. [DMN Industr.

Genèe, Bul. Soc. Bot. ... Cetin de Société des Arts de Genève. Classe d'industrie et de commerce. Genève. $8^{\circ}$.

$[\mathrm{BCE}$

* Bulletin des travaux de la Société botanique de Genève. Genève. $8^{\circ}$.

Genève, Jardinier Suisse..

Le Jardinier suisse. Organe de la Société helrétique d'horticulture de Genève. Genève. $8^{\circ}$.

Gemòe, Mém. Inst. Nat... Mémoires de l'Institut national genevois. Genève. 4\%

Genève, Mém. Soc. Phys...

* Mémoires de la Société de physique et d'histoire naturelle de Genève. Genève. $4^{\circ}$.

Genèce, Trav. Lab. Thérap. "Traraux du Laboratoire de thérapeutique expérimentelle de l'Unirersité de Grenève. Genève. $8^{\circ}$. [OQR

Globe, Genève .. . . * * Le Globe. Journal géographique. Genève. $8^{\circ}$.

[JNP

46

Jahrb. Schveiz. Alpencl.,

*Jahrbuch des schweizerischen Alpenclubs. Bern. $8^{\circ}$.

[FHJ

Jahrb. Schweiz. Electrot. Ver., Zwirich

Internat. Monatsschr. Bek. Trinksitten, Basel

Journ. Agricult. Suisse, Genève

*Jahrbuch des schweizerischen elektrotechnischen Vereins. Annuaire de l'Association suisse des Electriciens. Zürich. 8०. [BC

Internationale Monalsschrift zur Bekämpfung der Trinksitten. Revue mensuelle internationale contre la boisson. Basel. $8^{\circ}$.

Journal d'Agriculture suisse. Le Cultivateur de la Suisse romande et la Ferme suisse réunis. Genève. $8^{\circ}$. [DMN

Journ. Forest. Suisse, Berne Juurnal forestier suisse. Berne. $8^{\circ}$. [HMN Journ. Soc. Agricult. Journal de la Société d'Agriculture de la Suisse Rom., Lausanne

Jonrn. Stisse Phot., Lausanne Suisse romande. Lausanne. $8^{\circ}$.

[DMN

Journal suisse des photographes. Schweizerische Photographenzeitung. Lausanne. 4\%.

Journal télégraphique. Berne. $4^{\circ}$. $\quad$ BC

48

50

51

52

53

54.

Journ. Télégr., Berne $\quad$.. Journal têlegraphique. Berno. $40 . .2$

Kathol.Schweizerbl.,Luzern Katholische Schweizerblätter. Organ der schweizerischen Gesellschuft für katholische Wissenschaft und Kunst. Luzem. $8^{\circ}$.

Kraft \& Licht, Zibrioh .. Kraft und Licht. Zeitschrift für Fabrikbetrieb, Wasserversorgung, Beleuchtungswesen und Installation. Zürich. $4^{\circ}$. $[\mathrm{BCF}$

- Zeitschriften, die mit Ihrem ganzen Inhalt in den Bereich des Katalogs fallen. 
Landw. Jahrb. Schweiz, Landwirtschaftliches Jahrbuch der Schweiz.| Bern. Bern. $8^{\circ}$.

Lausanne, Bul. Mens. Bulletin mensuel. Seul Organe officiel de la Sages.Femmes Société vaudoise des Sages-Femmes. Lausanne. $8^{\circ}$.

Lausanne, Bul. Soc. Sci. *Bulletin de la Société raudoise des sciences Nat. naturelles. Lausanne. $8^{\circ}$.

Lausanne, Bul. Soc. Vaud. Bulletin de la Société vaudoise d'agriculture et Agric.

Lausanne, Bul. Soc. Vét... de viticulture. Lausanne. $\mathbf{8}^{\circ}$.

DMN

*Bulletin de la Société vaudoise des vétérinaires. Lausanne. $8^{\circ}$.

Lausanne, Journ. Soc. Journal de la Société d'horticulture du canton Hortic. Vaud.

Lausanne, Observ. Météor. de Vaud. Lausanne. $8^{\circ}$.

*Observations météorologiques faites à la station météorologique du Champ-de-l'A ir. Lausanne. $4^{\circ}$.

Luzєrn, Mitt. Natf. Ges... * Mitteilungen der naturforschenden Gesell. schaft in Luzern. Luzern. $8^{\circ}$.

Machine, Genève .. . . La Machine. Revue scientifique et industrielle de la Suisse occidentale. Genève. 4\%.

Messager Suisse Rom., Fribourg

Le Messager. Journal agricole et Organe des Sociétés ornithologiques de la Suisse romande. Fribourg. $4^{\circ}$.

[DMN

Mitt. Ges. Schweiz. Landw., Zürich

Mitteilungen der Gesellschaft schweizerischer Landwirte. Zürich. $8^{\circ}$.

[DMN

Mitt.Schweiz.Landw.-Dep.,

Bern, v. Bul. Dép. Féd. Agricult., Berne

Musée, Neuchâtel .. ..

Musée neuchâtelois. Recueil d'histoire nationale et d'archéologie. Neuchâtel. $8^{\circ}$.

N. Denkschr. Schweiz. Ges. Natro., Zurich

*Neue Denkschriften der allgemeinen schweizerischen Gesellschaft für die gesammten Naturwissenschaften. Nouveaux Mémoires de la Société helvétique des sciences naturelles. Zürich, etc. $4^{\circ}$.

Neuchâtel, Bul.Soc. Géogr. *Bulletin de la Société neuchâteloise de géographie. Neuchâtel. $\mathbf{8}^{\circ}$.

Neuchátel, Bul. Soc. Sci. *Bulletin de la Société neuchâteloise des sciences naturelles. Neuchâtel. $8^{\circ}$. Nat.

Porrentruy, Actes Soc. Actes de la Société jurassienne d'émulation. Jurass. Emul. Porrentruy, etc. $8^{\circ}$.

Prakt. Forstwirt Schweiz, Der praktische Forstwirt für die Schweiz. 
Résumé Météor., Genève .. $\quad$ Résumé météorologique de l'année. Genève. $8^{\circ}$.

Rev. Electr., Berne $\quad$.. Revuede l'électricité et de l'éclairage. Berne. $4^{\circ}$.

Rev. Hortic. Suisse Rom., Revue horticole et viticole de la Suisse romande. Genève

Genève. $8^{\circ}$.

78

Rev. Internat. Apieult., Nyon

Rev. Méd. Suisse Rom.,

Revue internationale d'apiculture. Nyon. $8^{\circ}$.

* Revue médicale de la Suisse romande. Genève. $8^{\circ}$.

[OQR

Genève

Rev. Suisse Cathol, Fri. bourg

Rev. Suisse Phot., Geneve

Revue suisse de Photographie. Genève et Paris. $8^{\circ}$.

[CD

Rev. Suisse Zool., Genève. .

* Revae suisse de Zoologie. Annales de la Société zoologique suisse et du Musée d'histoire naturelle de Genève. Genève. $8^{\circ}$.

san.-Demogr. Wochenbull., Bern

Schaffhausen, Mitt. Schweiz. Entomol. Ges.

Schweiz.-Arch. Thierheilk., Zürich

Schweis. Areh. Volksk., Ziirich

Schweiz.-Bawer, Bern ...

Schweiz. Bienenztg, Aarau Schveiz. Bl. Electrot., Bern

Schveiz. Bl. Gesundhtspfl., Zürich

Schweiz. Bl. Ornithol, Zïrich

Schreiz. Electrot. Ztg., Zürich

Schweiz. Fischereiztg., Pfïfikon

Schweiz. Gartenbau, Ziurich

Schweiz.-Geflügelhof, Aaran

Schweiz. Hebammenstg, Aaraw.

Schueiz. Hydrom. Beob., Beru.

Seluveis. Landw. Centralbl., Frawenfeld
*Sanitarisch-demographisches Wochenbulletin der Schweiz. Bulletin hebdomadaire démographique et sanitaire suisse. Bern. $8^{\circ}$.

[DOQR

* Mitteilungen der schweizerischen entomologischen Gesellschaft. Bulletin de la Société entomologique suisse. Schaffhausen. $8^{\circ}$.

[N

"Schweizer-A rchiv für Thierheilkunde. Zürich. $8^{\circ}$.

$[\mathrm{N}$

Schweizerisches Archiv für Volkskunde. Zürich. $8^{\circ}$.

Der Schweizer-Bauer. Bernische Blätter für Landwirtschaft. Bern. Fol.

[DMN

Schweizerische Bienenzeitung. Aarau. $8^{\circ}$. [N

Schweizerische Blätter für Elektrotechnik und das gesammte Beleuchtungswesen. Bern. $4^{\circ}$.

$[\mathrm{BC}$

*Schweizerische Blätter für Gesundheitspflege. Zugleich Korrespondenzblatt für örtliche Gesundheitsbehörden. Zürich. $8^{\circ}$.

*Schweizerische Blätter für Ornithologie und Kaninchenzucht. Zürich. $4^{\circ}$.

[N

Schweizerische elektrotechnische Zeitung. Zürich. $4^{\circ}$.

[BC

Schweizerische Fischereizeitung. Pfäffikon. $8^{\circ}$.

[N

Der Schweizerische Gartenbau. Zürich. $\mathbf{8}^{\circ}$.

MN

Schweizer-Geflügelhof. Zeitschrift für Geflügel- und Kaninchenzucht. Aarau. $4^{\circ}, \quad[\mathrm{N}$

Schweizerische Hebammenzeitung. Aarau. $4^{\circ}$.

[OQ

- Schweizerische hydrometrische Beobachtun. gen. Bern. Fol.

$[\mathrm{J}$

Schweizerisehes landwirtschaftliches Central. blatt. Organ der Gesellschaft schweizerischer Landwirte. Frauenfeld. 8०.

[DMN

87

81

5

9


Schweiz. Landw. Zeitschr., Schweizerische landwirtschaftliche Zeitschrift. Aarau.

Aarau. $8^{\circ}$.

[DMN

Schweiz. Milchztg, Schaff. hausen.

Schweizerische Milchzeitung und landwirtschaftliche Umschau. Schaffhausen. Fol.

100 Schweiz. - Pflanzenfreund,
Rüti.

Schweizer-Pflanzenfreund. Rüti (Zürich). $8^{\circ}$

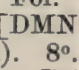

101

Schweiz. Statistik, Bern ..

Schweizerische Statistik. Statistique Suisse. Bern. $4^{\circ}$.

[FNP

Schweiz. Vierteljahrschr. Zahnheilk., Zürich.

*Schweizerische Vierteljahrschrift für Zahnheilkunde. Revue trimestrielle suisse d'odontologie. Zürich. $8^{\circ}$. [OQR

Schweiz. Wochenschr., Chem., Zïrich.

*Schweizerische Wochenschrift für Chemie und Pharmacie. Journal suisse de chimie et de pharmacie. Zürich. $\mathbf{8}^{\circ}$.

[CDEQ.

Schweiz. Zeitschr. Forstwesen, Bern.

Schweizerische Zeitschrift für das Forstwesen. Bern. $8^{\circ}$.

[FMN

Schweiz. Zeitschr. MetallIndustrie, Zürich

Schweiz. Zeitschr. Obst- \& Weinbau. Frauenfeld

Schweizerische Zeitschrift für Metall - und Maschinenindustrie. Zürich. $4^{\circ}$. [BD

Schweizerische Zeitschrift für Obst- und Weinbau. Frauenfeld. $\mathbf{8}^{\circ}$.

[FMN

Schweiz. Zeitschr. Strafrecht, Bern.

Sci. Prat., Vevey .. ..

Schweizerische Zeitschrift für Strafrecht. Revue pénale suisse. Bern. $8^{\circ}$. [P

La science pratique. Journal mensuel de Procédés et Recettes modernes. Vevey. $4^{\circ}$.

Soc. Entomol., Zürich . ..

St. Gallen, Ber. Natw. Ges.

St. Gallen, Mitt. Ostschweiz. Geogr. Ges.

Statistique suisse, Berne, $v$. Schweiz. Statistik, Bern.

Suisse Universitaire, Genève

*Societas entomologica. Zürich. $4^{\circ}$. [N

*Bericht über die Thätigkeit der St. Gallischen naturwissenschaftlichen Gesellschaft. St. Gallen. $8^{\circ}$.

*Mitteilungen der ostschweizerischen geo- 112 graphisch-kommerziellen Gesellschaft. Gallen. $8^{\circ}$.

102

103

104

105

106

107

108

1.09

110

111

La Suisse Universitaire. Genève. $8^{\circ}$.

Thierwelt, Aarau ..

Die Thierwelt. Zeitung für Ornithologie, Geflügel- und Kaninchenzucht. Aarau. $4^{\circ}$.

Thurganer Bl. Landw., Thurgauer Blätter für Landwirtschaft (Wein-, Eschlikon.

Obst-, Gartenbau und Bienenzucht), Eschlikon. $4^{\circ}$.

[DMN

Verh. Schweiz. Natf. Ges., Aarau.

*Verhandlungen der schweizerischen naturforschenden Gesellschaft. Aarau, Basel, etc. $8^{\circ}$.

Volkswirtsch. Bl. GraubünVolkswirtschaftliches Blatt für den Kanton den, Chur.

Graubünden. Organ für Land-, Forst- und Alpwirtschaft und das Gewerbewesen. Chur. 4\%.

[MNP

* Zeitschriften, die mit ihrem ganzen Inhalt in den Bereich des Katalogs fallen. 
Wädensweil, Jahresb. Ver- Jahresbericht der deutsch-schweizerischen Versuchsstation, Zirrich suchsstation und Schule für Obst-, Wein- und Gartenbau in Wädensweil. Zürich. $8^{\circ}$. [M

Zeitschr. Schweiz. Statis-

Zeitschrift für schweizerische Statistik. Journal de statistique suisse. Herausgegeben von der Centralkommission der schweizerischen statistischen Gesellschaft. Berm. 40. tik, Bern.

Zürcher Bl. Tierschutz, Zürich

Zürcher Blätter für Tierschutz. Zürich. $8^{\circ}$.

Zürich, Ann. Schweiz.

* Annalen der schweizerischen meteorologischen Meteor. Centralanst.

Zirrich, Mitt. Ant. Ges. ... Centralanstalt. Zürich. $4^{\circ}$.

Mitteilungen der antiquarischen Gesellschaft in Zürich. Zürich. $4^{\circ}$.

Ziirich, Mitt. Schweiz. Forstl. Versuchsw.

Mitteilungen der schweizerischen Centralanstalt für das forstliche versuchswesen. Zürich. $8^{\circ}$.

Zürich, $\bar{V}$ erh. Techn. Ges.

Verhandlungen der technischen Gesellschaft in Zürich. Zürich. $8^{\circ}$.

[BCD

Zirich, Vierteljahrsch. Natf. Ges.

*Vierteljahrschrift der naturforschenden Gesellschaft in Zürich. Zürich \& München. $8^{\circ}$.

Zïrich, Wetterber.

Wetterbericht der schweizerischen meteorolo. gischen Centralanstalt. Bulletin du Bureau Central météorologique suisse. Zürich. $4^{\circ}$. [F

* Zeitschriften, die mit ihrem ganzen Inhalt in den Bereich des Katalogs fallen. 


\section{UNITED KINGDOM.}

Aeronaut. J., London Agric. Students Cirencester

Archaol. Ael., London and Newcastle

Croydon, Trans. Nat. Hist. Sci. Soc.

Field Nat. Q., Edinburgh

Hertford, East Herts Archrol. Soc.

London, J.R. Inst. Brit. Archit.

London, Proc. Anat. Soc. .

London, Proc. Midl. Inst. Min. Civ. Mech. Engin.

Montgomery Oswestry

N. Phytol., London

Num. Chron., London and Paris

Rep. Mus. Ass., Canterbury

Wye, J. South - Eastern Agric. Coll.

Wye, Rep. South-Eastern Agric.

Electr. Times, London _. The Electrical Times, London.
477 students at the Royal Agricultural College, Cirencester. Cirencester.

Archæologia Aeliana: or Miscellaneous Tracts relating to Antiquities prepared by the Society of Antiquaries of Newcastle-upon-Tyne. London and Newcastle.

Transactions of the Croydon Natural History and Scientific Society.

The Field Naturalist Quarterly, Edinburgh ..

East Herts Archæological Society. Transactions. Hertford.

Journal of the Royal Institute of British Architects. London.

London, Proceedings of the Anatomical Society [v. J. Anat. Physiol., London.]

Proceedings of the Midland Institute of Mining, Civil and Mechanical Engineers.

Collections Historical and Archrological, relating to Montgomeryshire and its borders: issued by the Powys-land Club for the use of its members. Oswestry.

New Phytologist. London.

Numismatic Chronicle and Journal of the Numismatic Society. London and Paris.

Report of the Museums Association, Canterbury

The Journal of the South-Eastern Agricultural College, Wye, Kent. London and Ashford.

Roports of the South-Eastern Agricultural College, Wye, Kent. London and Ashford. 


\section{UNITED STATES OF AMERICA.}

Albasy, Univ. N.Y., Bull. The University of the State of New York. Bulletin. Albany, N.Y.

Albany, Univ. N.Y., Re- University of the State of New York, Regents gents Bull.

Bulletin. Albany, N.Y.

[A-R

Albany, Univ. N.Y., Rep. Regents

University of the State of New York. Annual Report of the Regents. Albany, N.Y. [A-R

Amer. Inv., Washington, D.C.

Amer. Mus. J., New York, The American Inventor. Washington, D.C.

The American Museum Journal. American Museum of Natural History. New York, N.Y.

KPN

Amer. Ornith., Worcester, Mass.

Ann Arbor, Cont. Bot. Lab. Univ. Mich.

Ann. Arbor, Mich., Univ. Bull.

Atl. Slope Nat. Narbeth, $\mathrm{Pa}$.

American Ornithology. For the Home and School. Worcester, Mass.

Contributions from the Botanical Laboratory of the University of Michigan. Ann Arbor, Mich.

The Atlantic Slope Naturalist. Narbeth, Pa. ..

Baltimore, Md., Proc. Ass. Aner. Anat.

Berkley Unio. Cal., Chron.

Proceedings of the Association of American Anatomists. [Included in Amer. J. Anat., Baltimore, Md.]

The Eniversity Chronicle. University of California, Berkeley, Cal.

Berkeley, Univ. Cal., Pub. Bot.

University of California Publications. Botany. Berkeley, Cal.

Berkeley, Univ. Cal., Pub. Physiol.

Berkeley, Univ. Cal., Pub. Zool.

Boulder, Univ. Colo. Stud.

Brooklyn, N.Y., Inst. Arts Sci., Cold Spring Harbor Monog.

Bryn Mavr, Pa., Bryn Marer Coll. Monogr.

University of California Publications. Physiology. Berkeley, Cal.

University of California Publications. Zoology. Berkeley, Cal.

The University of Colorado Studies. Boulder, Colo.

Cold Spring Harbor Monographs. Brooklyn Institute of Arts and Sciences. Brooklyn, N.Y.

Bryn Mawr College Monographs. Bryn Mawr, 546 Pa.

Chicago, IIl., $\boldsymbol{S p}_{p}$. Pub. Special Publications. The Chicago Academy of Acad. Sci. Sciences. Chicago, Ill.

Cincinnati, Ohio, Bull. Bulletin of the Lloyd Library of Pharmacy and

Materia Medica. Cincinnati, Ohio. 
Cincinnati, Ohio Univ. Cin- The University of Cincinnati Bulletin. Cincincin. Bull. nati, Ohio.

Columbus, Cont. Bot. Lab. Contributions from the Botanical Laboratory of Ohio Univ. Ohio State Universily, Columbus, Ohio.

Columbus, Ohio, Acad. Sci., Ohio States Academy of Sciences. Special Sp. Paprs.

Columbus, Rep. Ohio Acad. Sci.

Cont. N. Amer. Ornith., Longwood and Concord, Mass. Papers. Columbus, Ohio.

[A-R

Annual Report of the Ohio State Acadeny of Science. Columbus, Ohio. $\quad[\hat{\mathbf{A}}-\mathbf{R}$ Contributions to North American Ornithology, by Reginald Heber Howe, Jr. Longwood and Concord, Mass.

Drug. Cir. Chem.Gaz., New York, N.Y.

Indianapolis, Proc. Ind. Engin. Soc.

J. Geog., Lancaster, Pa...

J. Maine Ornith. Soc., Fairfield

J. Med. Res., Boston, Mass.

Lansing, Rep. Mich. Acad. Sci.

Lawrence, Kan. Univ. Sci. Bull.

Manila, Bull. Philippine Mus.

Missonla, Bull.Univ. Mont.

Myc. notes, Cincinnati,Ohio

New York, N.Y.,Cont.Dept. Bot. Columbia Univ.

New Fork, N.Y., Trans. Amer. Inst. Elec. Engin.

New York, N.Y., Trans. Amer. Soc. Mech. Engin.

North Dakota, Geol. Surv. Rep:, Bismark
Druggisti' Circular an $\lambda$ Chemical Gazette, New York, N.Y.

The Journal of Geography. Lancaster, Pa. [M The Journal of the Maine Ornithological Society, Fairfield, Me.

Journal of Medical Research. Continuation of the Journal of the Boston Society of Medical Sciences. Boston, Massachusetts.

Report of the Michigan Academy of Science. Lansing, Mich.

The Kansas University Science Bulletin. Lawrence, Kan. [Includes Kansas University Quarterly.]

Bulletins of the Philippine Museum, Manila. [GP

Bulletin University of Montana. Missonla, Mont.

$[\mathbf{A}-\mathbf{R}$

Mycological Notes. Cincinnati, Ohio. [M

Contributions from the Department of Botany, Columbia University. New York, N.Y. [M Transactions from the American Institute of Electrical Engineers. New York, N.Y.

Transactions of the American Society of Mechanical Engineers. New York, N.Y.

State Greological Survey of North Dakota. Biennial Report. Bismark, N.

[H
565

551

552

563

517

576

548

549

577

564

5อ๊ 0

559

555 
Philadelphia, Pa., Trans. Transuctions of the American Electro-Chemical A mer. Electroch. Soc.

Society. Philadelphia, $\mathbf{P a}$.

Philadelphia, Univ., Pa., Cont. Zool. Lab.

Publications of the Unirersity of Pennsylvania. Contributions from the Zoological Laboratory. Philadelphia, $\mathrm{Pa}$.

Pittsburqh, Pa., Pub. Car. Pubiications of the Carnegie Museum. Pittsnegie Mus.

burgh, $\mathbf{P a}$.

[G.P.

Princeton. N.J., Unir. Princeton University Bulletin. Princeton, N.J. Bull.

Proc. Amer. Ass. Adv. Sci., Washingtow, D.C. [ formerly Easton Pa.]

Proceedings for the Amer. Ass. for the Advancement of Science. Washington, D.C.

[C]

581

553

Rhode Island Ornith., Notes on Rhode Island Ornithology. Bristol,

583 Bristol, R.I.

\section{R.I.}

San Francisco, Cal., Sierra Cl. Bull.

Santa Barbara, Cal., Bull. Soc. Nat. Hist.

The Sierra Club Bulletin. San Francisco

Bulletin of the Santa Barbara Society of Natural History. Santa Barbara, Cal.

Termont, Rep. Geol., Bur. lington.

Report of the State Geologist on the Minerul Industries and Geology of certain areas of Vermont. Burlington, Vt.

Washington, D.C., U.S. Dept. Agric. Bur. Plant Ind., Bull

Washington, D.C., Bull. U.S. Dept. Agric. Libr.

Wis. Engin., Madiso

letin. Washington, D.C [M The Wisconsin Engineer. University of Wisconsin Engineering Association. Madison, Wis.

Warcester, Mass., Pub. Publications of the Clark Unirersity Library. Clark Univ. Libr. Worcester, Mass. 


\section{VICTORIA (AUSTRALIA).}

Melbourne, Proc. Soc.Chem.|Melbourne, Proceedings of the Society of Ind., Vict. Chemical Industry. Victoria. Reprinted from the Chem. Drugg. Austral. [D

Vict. Ann. Rep. Cham. Annual Report of the Chamber for Mines, VicMines, Melbourne Vict. Journ. Dep. Agric., toria. Melbourne. 





\section{PLEASE DO NOT REMOVE}

CARDS OR SLIPS FROM THIS POCKET

\section{UNIVERSITY OF TORONTO LIBRARY}

$\mathrm{Z}$ International catalogue of 7403 scientific literature I68 Supplementery list of journals Suppl.

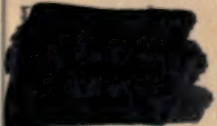


